\title{
EPSAT-SG: a satellite method for precipitation estimation; its concepts and implementation for the AMMA experiment
}

\author{
J. C. Bergès ${ }^{1}$, I. Jobard ${ }^{2,3}$, F. Chopin ${ }^{2}$, and R. Roca ${ }^{2}$ \\ ${ }^{1}$ PRODIG, Université Paris 1, 75005 Paris, France \\ ${ }^{2}$ LMD, IPSL/CNRS, Ecole Polytechnique, 91128 Palaiseau, France \\ ${ }^{3}$ Univ. Paris-Sud, 92296 Chatenay, France
}

Received: 23 June 2009 - Revised: 7 October 2009 - Accepted: 31 October 2009 - Published: 27 January 2010

\begin{abstract}
This paper presents a new rainfall estimation method, EPSAT-SG which is a frame for method design. The first implementation has been carried out to meet the requirement of the AMMA database on a West African domain. The rainfall estimation relies on two intermediate products: a rainfall probability and a rainfall potential intensity. The first one is computed from MSG/SEVIRI by a feed forward neural network. First evaluation results show better properties than direct precipitation intensity assessment by geostationary satellite infra-red sensors. The second product can be interpreted as a conditional rainfall intensity and, in the described implementation, it is extracted from GPCP-1dd. Various implementation options are discussed and comparison of this embedded product with 3B42 estimates demonstrates the importance of properly managing the temporal discontinuity. The resulting accumulated rainfall field can be presented as a GPCP downscaling. A validation based on ground data supplied by AGRHYMET (Niamey) indicates that the estimation error has been reduced in this process. The described method could be easily adapted to other geographical area and operational environment.
\end{abstract}

Keywords. Meteorology and atmospheric dynamics (Precipitation; Tropical meteorology; Instruments and techniques)

\section{Introduction}

Rainfall is a key parameter both for energy cycle studies and environment monitoring. For example, early warning systems in agronomy and epidemiology rely mainly on precipitation mapping and, despite a deep international commitment in this domain, getting this information timely and accurately

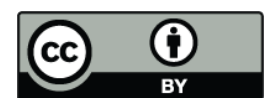

Correspondence to: J. C. Bergès (jean-claude.berges@univ-paris1.fr) is still a sensitive issue (Tefft et al., 2006). The global ground observation network is by no mean sufficient as it lacks the adequate density and data quality. Moreover such a network is costly to operate and only few land area, mostly concentrated in mid-latitude, are properly covered. This issue is very sensitive in inter-tropical area where early warning systems, crop monitoring and hydrological models require accurate estimation of an highly variable phenomenon. A more detailed discussion about rainfall variability and its impact on runoff estimates can be found in Balmes et al. (2006).

To overcome this limitation, meteorological satellite information has been integrated in rainfall estimation procedures. The Goes Precipitation Index (GPI) (Arkin, 1979; Arkin et al., 1987), has been the first widespread rainfall estimation method which is based on satellite data. It uses the geostationary thermal infrared channel $10.8 \mu \mathrm{m}$. A fixed temperature threshold $(235 \mathrm{~K})$ acts as rain/no rain indicator, then a fixed rain rate is applied to compute a rainfall intensity. Experimental rain rate observations have given estimates between $2.9 \mathrm{~mm} / \mathrm{h}$ and $3.7 \mathrm{~mm} / \mathrm{h}$ and a mean value of $3 \mathrm{~mm} / \mathrm{h}$ has been selected for the operational product. This method is often referred to as a Cold Cloud Duration (CCD): the rainfall duration on a given area is proportional to the number of pixels whose brightness temperature in the $10.8 \mu \mathrm{m}$ channel is lower than the threshold. GPI can be obviously computed and extended to geostationary satellites other than GOES. Nevertheless it relies on rough hypothesis and its validity is limited to the large time and space scales. In some extent this method has been enhanced by making global parameters region dependent and merging with ground data (Milford and Dugdale, 1990). An other refinement has been to integrate information about African Easterly Waves and storm type (Grimes and Diop, 2003).

Note that the main improvement has been integration of data from Low Earth Orbiting (LEO) satellites microwave sensors. These sensors allow for a more direct rainfall rate estimation based on absorption and scattering properties of

Published by Copernicus Publications on behalf of the European Geosciences Union. 
water and ice particles. Grody (1991) developed one of the first algorithms of this kind. Many further developments were brought in the framework of the Tropical Rainfall Measurement Mission (TRMM) including methods using data bases obtained from radiative transfer model coupled with cloud models (Kummerow et al., 1996, 2001; Viltard et al., 2006).

However microwave based algorithms raise two main issues: retrieval quality over land and a poor temporal sampling. Whereas geostationary satellite last generation offers a 15-min repetitiveness, at most one microwave measurement is available every three hours. Combining these two data sources appears as immediate improvement in rainfall estimation. Jobard and Desbois (1994) developed the Rain and Cloud Classification method. More recent developments of combined methods are using motion vectors (Joyce et al., 2004; Takahashi et al., 2006) or neural networks techniques (Hsu et al., 1997, 1999; Coppola et al., 2006).

Most of recent satellite precipitation algorithms are combining all possible data sources: microwave data from LEO satellites, infrared data from GEO satellites and surface data provided by radars or rain-gauges (Adler et al., 2003; Herman et al., 1997; Huffman et al., 2007; Kubota et al. 2007). A more complete review of global precipitation products can be found in Gruber and Levizzani (2008) and in Levizzani et al. (2007).

This paper will present EPSAT-SG (Estimation of Precipitation by SATellite-Second Generation), a new method frame for rainfall estimation procedures and then its first implementation for the AMMA experiment. AMMA (African Monsoon Multi-scale Analysis) is an international scientific group focusing on the West African Monsoon and the related interactions at different scales. Intensive observation periods have been carried out in 2006 on various West-African sites. As a key element of water cycle analysis a fine scale rainfall intensity product has been elaborated to be integrated in the database.

After a presentation of the data, the general frame of the method will be described and finally the AMMA implementation will be detailed in three sections: input predictors selection, statistical procedure design and rainfall potential intensity computation. The last sections will be dedicated to the actual rainfall estimation and its validation.

\section{Data}

The geostationary satellite data are provided by Meteosat Second Generation (MSG) Spinning Enhanced Visible and Infrared Imager (SEVIRI). Two area will be considered: a large one covering the central part of MSG field of view $\left(40^{\circ} \mathrm{N}-40^{\circ} \mathrm{S} / 40^{\circ} \mathrm{W}-40^{\circ} \mathrm{E}\right)$ and a smaller one corresponding to the AMMA sub-regional window $\left(25^{\circ} \mathrm{N}-0^{\circ} / 25^{\circ} \mathrm{W}-\right.$ $\left.25^{\circ} \mathrm{E}\right)$. Hereafter the first area will be referred to as Africa and the second one as AMMA. The observation period run from May to October 2004 and 2006. On this domain all the MSG infrared channels have been collected in full resolution.

A rainfall reference value collocated with MSG dataset is requested to implement the EPSAT-SG method. Because of the scarcity of the West African ground radar network, one can only rely on a satellite product and a TRMM product has been selected. The precipitation radar (PR) has been preferred to the passive microwave sensor (TMI) for its better accuracy. Moreover using an estimator based on passive microwave should introduce a discontinuity on shoreline as only the $85 \mathrm{GHz}$ is usable on land. This choice has positive advantages: the view angle is similar between MSG and this instrument, the studied area is completely covered and the spatial resolution of the PR instrument is comparable to the MSG resolution ( $5 \mathrm{~km}$ versus $3 \mathrm{~km}$ at the nadir sub-satellite point). The precipitation data are extracted from the $2 \mathrm{~A} 25$ product (Iguchi et al., 2000). To avoid geo-localization errors due to geometry or time shift between TRMM and MSG, PR space resolution has been downscaled to $10 \mathrm{~km}$ using an averaging filter and each TRMM grid cell was associated with the MSG pixel closest to its center. When interpreting this product as a rainfall presence indicator, all non zero values are considered as rainy. Despite the narrow swath of the PR instrument (around $250 \mathrm{~km}$ ) the resulting collocated database are large enough to extract valid statistical trends. For each rainy season this database contains more than 5 million records for the AMMA area and 20 million for the Africa area.

Two coarse scale gridded rainfall intensity products are used: the GPCP-1dd and the TRMM 3B42 products. The GPCP-1dd product (Huffman, 2001) is a global precipitation product delivered on an operational basis in the frame of the Global Precipitation Climatology Project (GPCP). It integrates infrared data from GEO and LEO satellites, passive microwave data from LEO satellites and raingauge network analysis from the product of the Global Precipitation Climatology Center (GPCC). This product can be obtained in various resolution. The 3B42 is a similar global rainfall product giving more weight to TRMM data (Huffman et al., 2007).

The validation rain-gauges data, provided by the Regional AGRHYMET Center are described in Sect. 8.

\section{EPSAT-SG concept}

EPSAT-SG concept relies on the fact that whereas geostationary satellite infrared sensors are a valuable tool for cloud classification, the statistical relation between rainfall intensity and top cloud temperature is weak and unstable as there is no direct relation between rain rates and IR satellites brightness temperatures. However, there is a close relationship between IR information and presence of rainfall especially over tropical area (Arkin, 1979) where the most part of rainfall comes from convective clusters with cold tops. 


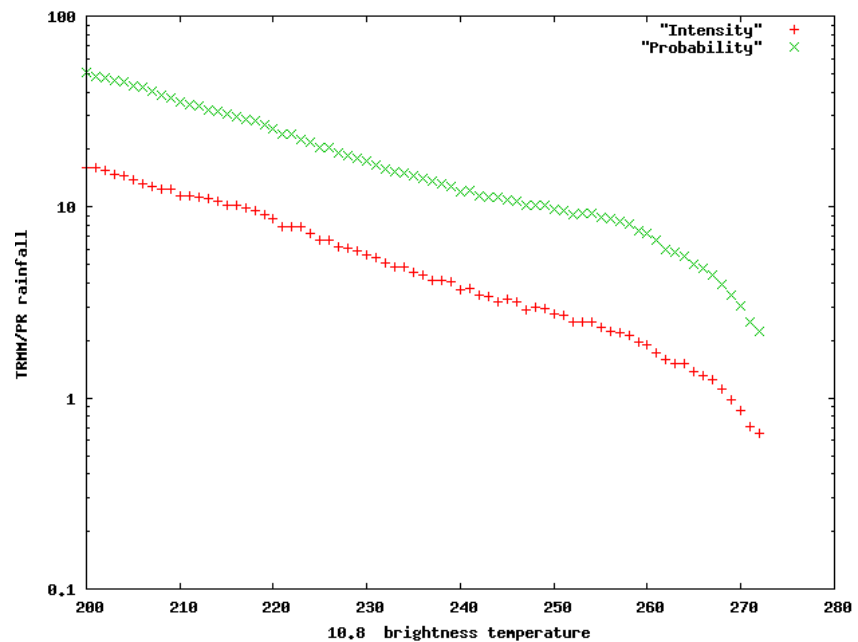

Fig. 1a. Empirical relationship between precipitation (rain rate and number of events) and $10.8 \mu \mathrm{m}$ brightness temperature. The mean precipitation rate (red curve) is in $\mathrm{mm} / \mathrm{h}$ and the mean number of rainfall events (green curve) is in percent. Both curves are plotted in logarithmic scale.

More direct measurements based on microwave sensors or rain-gauge networks provide much better estimates. But the geostationary data sampling is far superior both in space and in time and real-time acquisition of these data is easy to manage. The aim of a blended rainfall estimation method is to ingest this fine scale information into a coarser scale and/or discontinuous precipitation estimate. In some extents this issue is very similar to empirical downscaling of global circulation models on regional areas (von Storch et al., 2000). The main difference lies on nature of fine grid input parameters.

Assuming a sufficient database size, an empirical relation can be computed between infrared brightness temperatures and rainfall intensities. Using a ground radar network, Vicente et al. (1998) fit an exponential model through a logarithmic transformation. However this method raises the issue of the variance estimation error which is important for high precipitation rates. A way to mitigate this effect is to carry out the estimation on rainfall probability and not on rainfall intensity. On Fig. 1a the empirical relation between rain intensity and rainfall probability versus $10.8 \mu \mathrm{m}$ temperature is displayed with a logarithmic scale. The computations have been carried out on the 2006 whole African area and, for sampling and significance considerations, only the interval $200 \mathrm{~K}-273 \mathrm{~K}$ has been considered. In this interval, the shapes of these two curves look very similar and are consistent with an exponential model for a temperature lower than $260 \mathrm{~K}$. The corresponding coefficient of variation, ratio of the standard deviation by the mean is plotted in Fig. $1 \mathrm{~b}$. This non-dimensional coefficient allows to compare the signal to noise ratio of statistical relation. In the full range of temperature the coefficient of variation associated with the rainfall intensity is always greater than the probability coef-

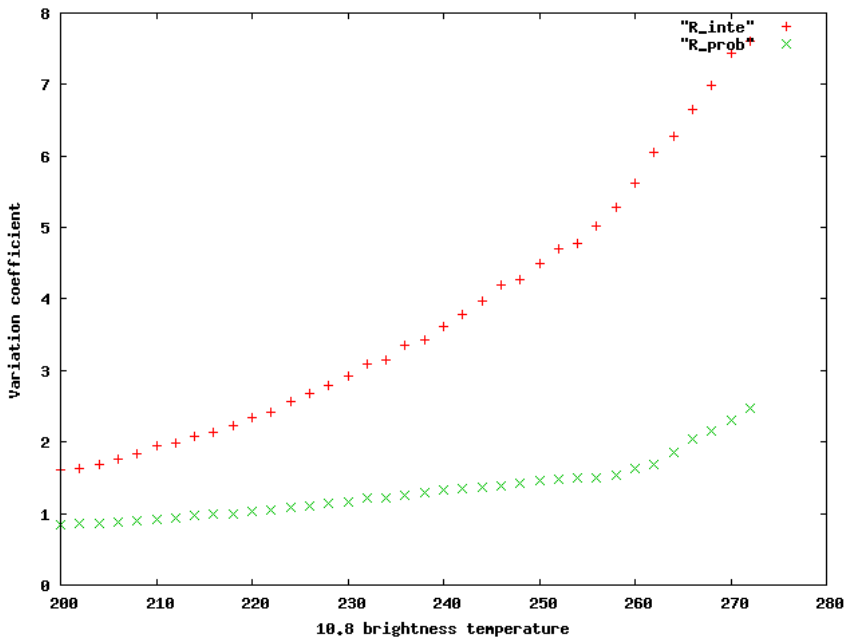

Fig. 1b. Variation coefficient for the rainfall intensity (red curve) and the rainfall probability (green curve) versus $10.8 \mu \mathrm{m}$ brightness temperature.

ficient and the minimal value of these two coefficient ratios is close to 2. This feature suggests that, in our database, the estimation of rainfall probability from cloud temperatures is much less noisy than for precipitation intensity.

Therefore the estimation is split in three steps: the production of a rainfall probability based on IR channels, the estimation of rainfall potential intensities by a downscaling process and the production of the accumulated rainfall. The rainfall potential intensity is a mean precipitation intensity conditioned by rain probability. Should the implementation use only one reference dataset for rainfall intensity the last step is straightforward. Otherwise the various potential intensity fields have to be merged. In an algorithm very similar to GPCP, the merging is then dependent on estimation variance. This last part of the algorithm will not be developed in this paper.

\section{Input data selection}

To implement this global frame the first step is the selection of an input predictor set. The predictors selection is deeply dependent on the observation system and on the study area, and this part describes the algorithm implemented for the AMMA experiment. These predictors are selected from the 12 visible and infrared channels of the SEVIRI radiometer on-board MSG.

The $10.8 \mu \mathrm{m}$ channel is used as a first order temperature factor. Located in a spectral window, its brightness temperature allows for a direct retrieval of cloud top altitude. Moreover all the meteorological satellite infrared sensors offered measurements in this wavelength and it was the base of the first results on satellite rainfall estimation (Arkin, 1979). 


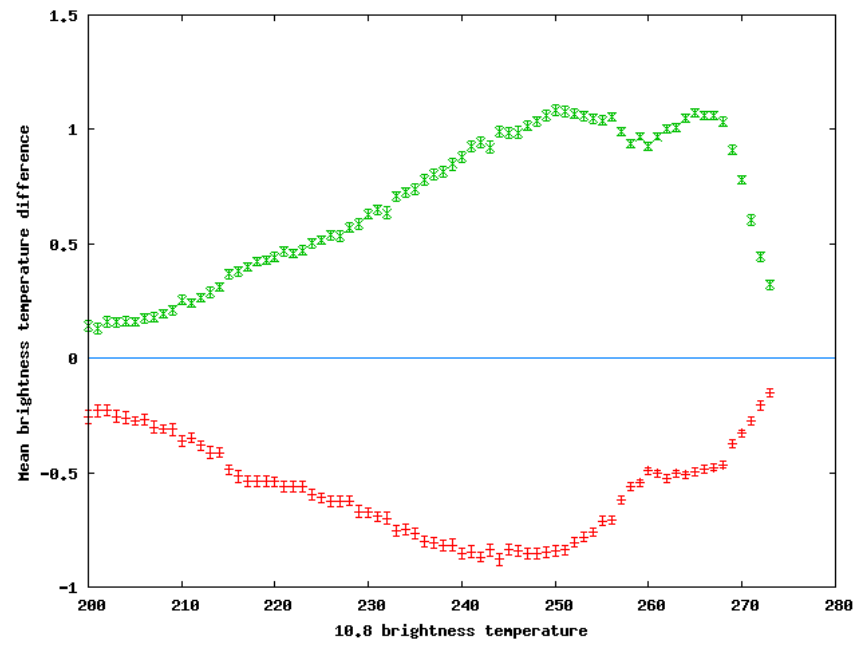

Fig. 2a. Difference of the mean value of $08.7 \mu \mathrm{m}$ and $12.0 \mu \mathrm{m}$ channels between non rainy and rainy pixels plotted versus $10.8 \mu \mathrm{m}$ brightness temperature in red and green respectively. Curves are plotted with error-bars. Both scales are in Kelvin.

At a first glance integrating information about solar backscattering radiation should enhance rainfall probability estimation. However the discontinuity between day and night should introduce a bias at the level of the diurnal cycle. As the temporal integration of validation data is scarcely shorter than one day correcting this bias should be a sensitive issue. Thus the three channels at $0.6 \mu \mathrm{m}, 0.8 \mu \mathrm{m}$ and $1.6 \mu \mathrm{m}$ have not been selected. The $3.9 \mu \mathrm{m}$ channel has been discarded also because of the different type of information provided during day and night-time, and of highly reflective background problems due to sun glint, bare soils or deserts. Moreover this channel accuracy is poor over cold clouds and thus it should introduce extra-noise in the statistical estimation.

SEVIRI integrates two split window channels: $8.7 \mu \mathrm{m}$ and $12.0 \mu \mathrm{m}$. The $12.0 \mu \mathrm{m}$ channel, primarily designed on the Tiros-N series, for sea surface temperature retrieval has demonstrated its efficiency for nephanalysis. It can help in discriminating semi-transparent cirrus as their brigthness temperature should be lower for $12.0 \mu \mathrm{m}$ than for $10.8 \mu \mathrm{m}$ (Derrien et al., 1993). It has been used by Inoue (1987) as an input for a statistical rainfall assessment. The $8.7 \mu \mathrm{m}$ channel can be used in association with $10.8 \mu \mathrm{m}$ for high altitude cirrus screening (Schmetz et al., 2002). Moreover it adds facilities to identify cloud phase (Wolters et al., 2008).

As a first assessment of the split window channels efficiency, the whole dataset has been split in rainy and non rainy pixels according to TRMM/PR. For each subset the mean brightness temperature for the $8.7 \mu \mathrm{m}$ and the $12.0 \mu \mathrm{m}$ channel has been computed, then the difference of these two mean temperatures has been plotted versus the $10.8 \mu \mathrm{m}$ temperature in Fig. 2a. The red curve represents the $8.7 \mu \mathrm{m}$ channel and the green the $12.0 \mu \mathrm{m}$. The effects are opposite but these two curves show similar patterns. When con-

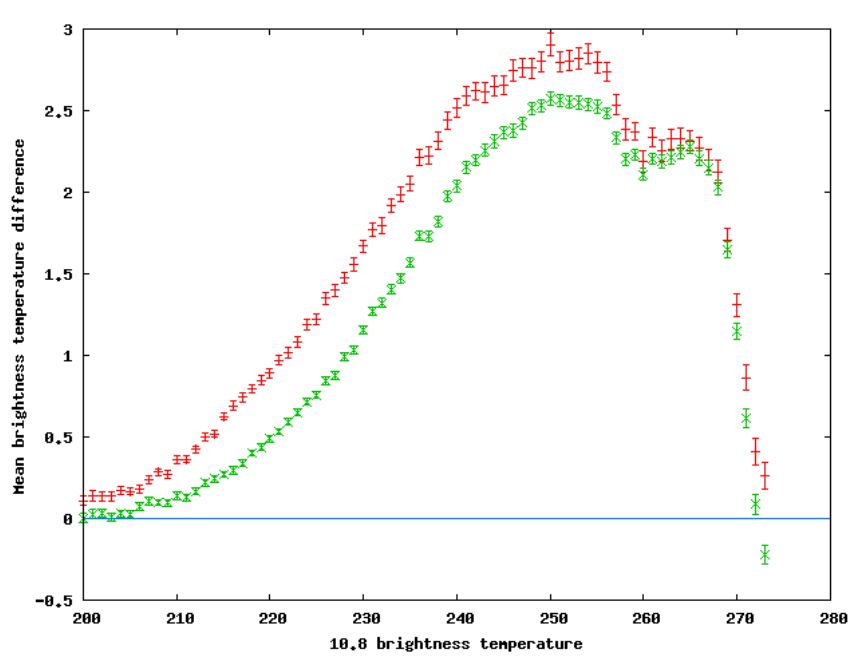

Fig. 2b. Difference of the mean value of $6.2 \mu \mathrm{m}$ and $7.3 \mu \mathrm{m}$ channels between non rainy and rainy pixels plotted versus $10.8 \mu \mathrm{m}$ brightness temperature in red and green, respectively. Curves are plotted with error-bars. Both scales are in Kelvin.

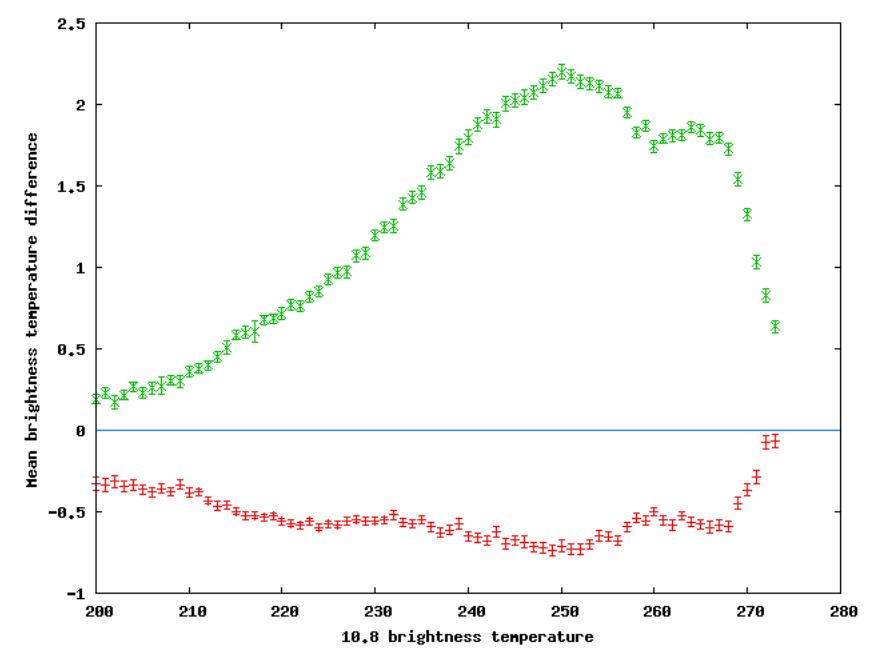

Fig. 2c. Difference of the mean value of $9.7 \mu \mathrm{m}$ and $13.4 \mu \mathrm{m}$ channels between non rainy and rainy pixels plotted versus $10.8 \mu \mathrm{m}$ brightness temperature in red and green respectively. Curves are plotted with error-bars. Both scales are in Kelvin.

sidering the $8.7 \mu \mathrm{m}$ (resp. $12.0 \mu \mathrm{m}$ ), on the whole range of $10.8 \mu \mathrm{m}$ temperatures the mean value for rainy pixels is always smaller (resp. greater) than for non rainy ones. The maxima of these curves indicate the area of best discrimination efficiency. Note that these maxima area are slightly shifted, the $8.7 \mu \mathrm{m}$ discriminating better at lower temperatures than the $12.0 \mu \mathrm{m}$.

The first water vapor channel has been introduced on Tiros-2 in 1960 to provide information about water vapor content. Two SEVIRI channels are located inside of the water vapor absorption band: $6.2 \mu \mathrm{m}$ and $7.3 \mu \mathrm{m}$. In a mean 
tropical atmosphere the peaks of their weighting functions are at $350 \mathrm{hpa}$ and $500 \mathrm{hpa}$. Although these channels have been designed to measure water vapor content at different levels they also contain information about cloud height (Nieman et al., 1993). Moreover, the difference between these two channels, correlated with water vapor content at the atmosphere higher levels, can be interpreted as a cloud precipitable water content (Schmetz et al., 2002). A complete description of these two channels can be found in (Santurette and Georgiev, 2005).

Figure $2 \mathrm{~b}$ is similar to Fig. 2a; the difference for the $6.2 \mu \mathrm{m}$ channel is plotted in red and for the $7.3 \mu \mathrm{m}$ channel in green. Due to the low layers absorption the higher temperatures are not significant. Elsewhere they display the same trend, continuously growing from $200 \mathrm{~K}$ until $255 \mathrm{~K}$. In this interval the order of magnitude of the difference is almost twice as much as for the split-window channels.

The $9.7 \mu \mathrm{m}$ channel belongs to the ozone absorption line; it offers facilities to evaluate the content of this component. But it can also be combined with other channels to evaluate the height of clouds and the air mass temperature (Kerkmann et al., 2005; Lattanzio et al., 2006). In a similar way the $13.4 \mu \mathrm{m}$ channel has been primarily designed for $\mathrm{CO}_{2}$ content observation. The difference between $13.4 \mu \mathrm{m}$ and $10.8 \mu \mathrm{m}$ channels can be used to discriminate convective cells from other clouds. Eyre and Menzel (1989) demonstrated that the combination of $13.4 \mu \mathrm{m}$ and $11.1 \mu \mathrm{m}$ channels of NOAA-7 satellite can be used in order to estimate cloudtop pressure which is highly correlated with altitude. It is particularly efficient to evaluate mid-level cloud heights. An important characteristic of these two channels is that the peak of their weighting function is lower than those of water vapor channels. In the same conditions as above, the maximum of $\mathrm{CO}_{2}$ channel is obtained at $830 \mathrm{hpa}$ and the maximum of ozone channel at the ground pressure. Thus they can supply a complementary information in the troposphere lower layers.

Figure 2c displays the difference graph for channels $8.7 \mu \mathrm{m}$ (red) and $13.4 \mu \mathrm{m}$ (green). Once again the difference sign is constant on the whole temperature interval but the behavior of these two curves is rather different. Whereas the red curve has a clear maximum around $250 \mathrm{~K}$, the green curve is almost flat. This feature should suggest that each channel has some capacity to filter non rainy events but the underlying phenomena are different.

Because of their relationship with cloud properties, all the SEVIRI thermal infrared channels $(6.2 \mu \mathrm{m}, 7.3 \mu \mathrm{m}, 8.7 \mu \mathrm{m}$, $9.7 \mu \mathrm{m}, 10.8 \mu \mathrm{m}, 12.0 \mu \mathrm{m}$, and $13.4 \mu \mathrm{m})$ are selected as input predictors. All these channels are highly correlated to a general temperature factor. It has to be underlined that multi-spectral thermal properties act as a second order effect against this factor. To improve the convergence efficiency, one of the channels is chosen as reference and as first input and the differences between this channel and the others are considered as inputs for the neural network. The use of these differences can be considered as a naive orthogonaliza-

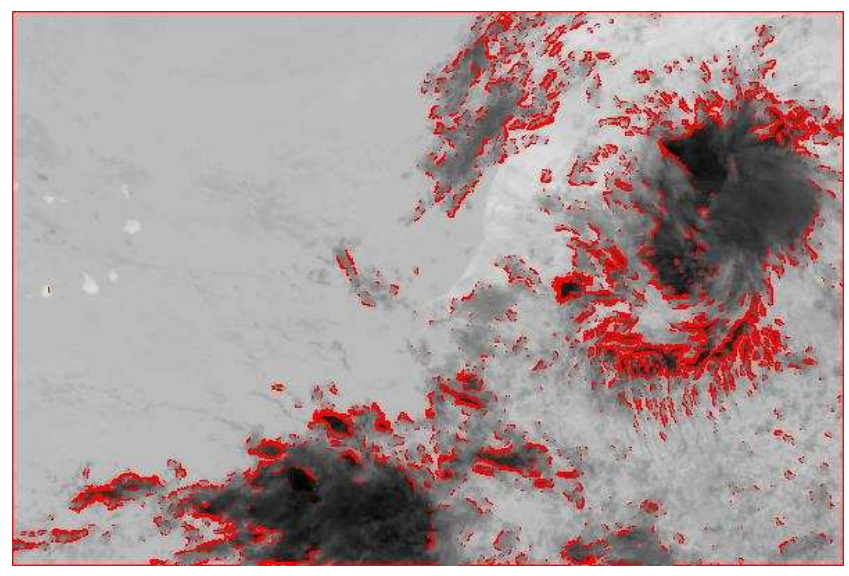

Fig. 3. The 5\% highest local variance values are plotted in red on the $8.7 \mu \mathrm{m}$ channel image $\left(20^{\circ} \mathrm{N}-11^{\circ} \mathrm{N} / 26^{\circ} \mathrm{W}-12^{\circ} \mathrm{W}\right)$. The local variance has been computed on a $3 \times 3$ window.

tion process between the global temperature factor and each thermal infrared channel. The choice of the reference channel does not influence the learning process of the neural network. As mentioned above, the $10.8 \mu \mathrm{m}$ channel is selected as a main temperature factor.

A local variance indicator of the $10.8 \mu \mathrm{m}$ channel is often used in order to discriminate convective cells from non rainy clouds (Adler and Negri, 1988; Jobard and Desbois, 1992). Underlying hypothesis is that top of clouds limited by an inversion layer would look flat whereas deep convection should be associated with a non-uniform cloud top temperature. A local variance or a slope are currently used as an input for rainfall estimation models, but the actual efficiency appears as moderate (Ba and Gruber, 2000). As a matter of fact the high variance values are mainly associated with cloud boundaries (Fig. 3) because of the contrast with the ground. In some extent, this feature is related to rainfall as the more active cells are generated in the front of convective systems, but the relation is still very indirect. In order to overcome partially this effect, other information have been chosen as inputs in the neural network. Both local variance of $10.8 \mu \mathrm{m}$ thermal IR channel and of $6.2 \mu \mathrm{m}$ water vapor channel are used. The absorption by water vapor in this channel is very high so that the surface and the lower layers of the atmosphere are totally masked, reducing the contrast of cloud edges. Also, the maximum temperature value in the 5 pixel $\times 5$ pixel window is selected in order to discriminate high values of spatial variance due to the contrast between clouds and ground (or high and low clouds) and those due to convective cells. Moreover, both local variance of $10.8 \mu \mathrm{m}$ thermal IR channel and of $6.2 \mu \mathrm{m}$ water vapor channel are used.

In the life cycle of a convective cell the maximum of precipitation occurs during the growing phase (Redelsperger, 1997). This time evolution is represented by a cooling index, difference between two successive $10.8 \mu \mathrm{m}$ images. Among 
Table 1. Neural network input list. The SEVIRI channels are denoted following the Eumetcast standard (i.e. IR_108 means infrared $10.8 \mu \mathrm{m})$.

\begin{tabular}{ll}
\hline SEVIRI multi-spectral indicators & IR_108 \\
& IR_108 - WV_062 \\
& IR_108 - WV_073 \\
& IR_108 - IR_087 \\
& IR_108 - IR_097 \\
& IR_108 - IR_120 \\
& IR_108 - IR_134 \\
\hline Temporal difference indicator & IR_108 - prec(IR_108) \\
\hline Local variance indicators & Var. 5x5 WV_062 \\
& Max. 5x5 WV_062 \\
& Var. 5x5 IR_108 \\
& Max. 5x5 IR_108 \\
\hline Altitude & Digital elevation model (SRTM) \\
\hline
\end{tabular}

other factors, a decrease of the local brightness temperature may be related to a convective cloud expansion phase and then to higher probabilities of rainfall while an increase of the local brightness temperature may correspond to a convective cloud dissipation phase and to lower probabilities of rainfall.

Orographic effects can produce rainy events with specific patterns. In order to take into account this phenomenon, the altitude information is selected as an input. Altitude data are extracted from the digital elevation model based on the Shuttle Radar Topography Mission (SRTM).

The selected predictors are summarized in Table 1. In some extent this set has some redundancy and the estimation procedure has to cope with this feature. But the important fact is that each input is related to rainfall and does not introduce significant noise.

As far as a statistical process is involved, a Principal Component Analysis (PCA) could be used to reduce the number of input predictors. This preliminary transformation would both enhance the computation speed and the results stability. But the PCA relies on linear correlation relevance and in order to assess its liability correlation coefficients have been computed with different stratifications. In Table 2a, correlation matrices computed according to a two months temporal stratification are displayed. These matrices are computed on the seven SEVIRI channels from $6.2 \mu \mathrm{m}$ to $13.4 \mu \mathrm{m}$ for the whole African continent. At a first glance, these results look consistent, both signs and magnitude of correlation coefficients are conserved among these three matrices. However this is a global feature which should be significant if precipitation were highly correlated with this main trend. A second stratification, based on a temperature threshold, has been introduced. Computation has been carried out on the same area from May to October 2006. The first matrix has been computed without any filtering and is therefore very similar to the previous one. For the second, a $273 \mathrm{~K}$ threshold has been applied eliminating almost all direct ground signal and for the third matrix the threshold has been set to $233 \mathrm{~K}$ in order to focus on convective processes. The discrepancy between these three matrices appears clearly (Table 2b). Even if only atmospheric phenomena are considered no regular patterns are observed and the extracted PCA factors would be highly dependent on the selected threshold. Replacing the predictor set with the first PCA factors would suppress some significant information for the low temperatures. It is a direct consequence of the the non linearity issue which has been previously mentioned.

\section{Statistical procedure design}

Estimating rainfall occurrence from this set of input predictors can be described as a non linear extension of a regression analysis or a multidimensional extension of histogram matching. Kiruno (1998) had to solve a similar problem when he designed an estimation process to retrieve precipitation from three satellite channels. A discretization interval has been set on each component to compute a threedimension table. This simple method estimates a precipitation rate for each node but is difficult to extend as the table size increases quickly with the predictors number and therefore a stable estimation would require a huge learning set. By contrast a linear regression would produce a stable but also inaccurate result. The number of degrees of freedom highlights this difference. Let $n$ be the number of input predictors, the regression has $n$ degrees of freedom whereas the multidimensional histogram matching has $\prod_{i=1, n} \operatorname{lev}(i)$ degrees of freedom where $\operatorname{lev}(i)$ is number of bins for the $i$-th predictor.

Feed forward neural networks appear as a compromise as their number of degrees of freedom is intermediate and dependent on the network architecture. Figure 4 is a graphical presentation of such a network. A set of hidden nodes acts as an intermediate between the predictors and the output of the network. The input of each hidden node is a linear combination of the input predictors, this value is then transformed by an activation function. The network output itself is a linear combination of the hidden nodes output. Once the network architecture is designed, the linear combination coefficients have to be set in order to fit at best with the learning data set. The number of coefficients to estimate can be related to the degree of freedom of the model, in a feed forward network it is $m n+m$ where $m$ is the hidden nodes numbers. The universal approximation theorem (Hornik, 1991) states that such a network could approximate any continuous function with one hidden layer and a finite number of hidden nodes. The key point is that the activation functions are continuous and non linear; the sigmoid function has been selected for EPSAT-SG implementation. 
Table 2a. Correlation matrices for three periods.

\begin{tabular}{lllllrrr}
\hline May-Jun & & & & & & & \\
\hline WV_062 & 1.000 & 0.970 & 0.682 & 0.865 & 0.920 & -0.051 & 0.931 \\
WV_073 & & 1.000 & 0.680 & 0.852 & 0.886 & 0.012 & 0.960 \\
IR_087 & & & 1.000 & 0.748 & 0.713 & -0.487 & 0.651 \\
IR_097 & & & & 1.000 & 0.930 & -0.311 & 0.893 \\
IR_108 & & & & & 1.000 & -0.220 & 0.904 \\
IR_120 & & & & & & 1.000 & 0.054 \\
IR_134 & & & & & & & 1.000 \\
\hline Jul-Aug & & & & & & & \\
\hline WV_062 & 1.000 & 0.966 & 0.654 & 0.840 & 0.905 & 0.134 & 0.922 \\
WV_073 & & 1.000 & 0.666 & 0.831 & 0.868 & 0.209 & 0.952 \\
IR_087 & & & 1.000 & 0.720 & 0.703 & -0.315 & 0.643 \\
IR_097 & & & & 1.000 & 0.941 & -0.156 & 0.889 \\
IR_108 & & & & & 1.000 & -0.087 & 0.900 \\
IR_120 & & & & & & 1.000 & 0.212 \\
IR_134 & & & & & & & 1.000 \\
\hline Sep-0ct & & & & & & & \\
\hline WV_062 & 1.000 & 0.972 & 0.646 & 0.891 & 0.950 & 0.072 & 0.944 \\
WV_073 & & 1.000 & 0.620 & 0.848 & 0.910 & 0.177 & 0.965 \\
IR_087 & & & 1.000 & 0.712 & 0.678 & -0.433 & 0.591 \\
IR_097 & & & & 1.000 & 0.943 & -0.176 & 0.881 \\
IR_108 & & & & & 1.000 & -0.041 & 0.914 \\
IR_120 & & & & & & 1.000 & 0.216 \\
IR_134 & & & & & & & 1.000 \\
\hline
\end{tabular}

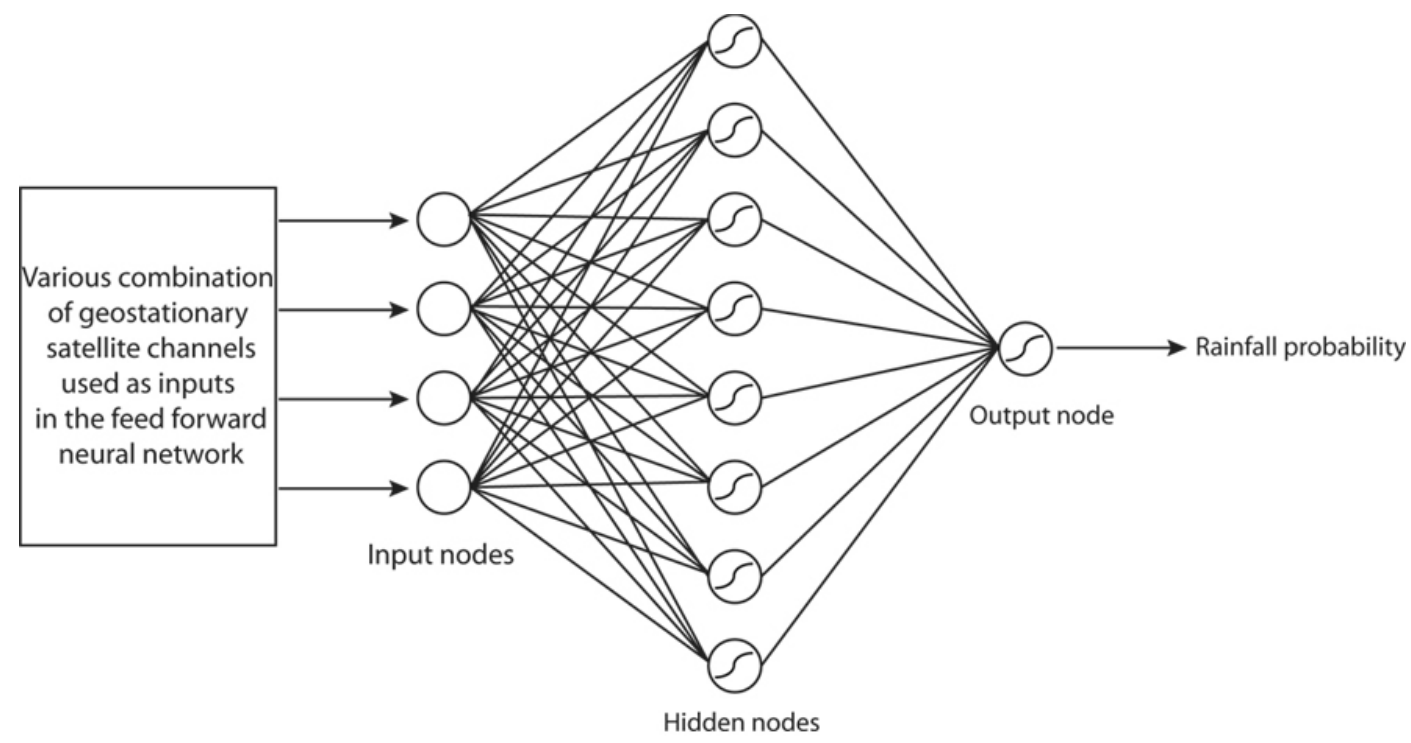

Fig. 4. Schematic representation of a feed forward neural network.

Setting the number of hidden nodes is mainly an heuristic issue. It is usually presented as a trade-off between result accuracy versus network training time and error propagation due to truncated computer arithmetic. Moreover increasing the number of hidden nodes could produce a network overtraining. A comprehensive discussion on this topic can be found in Walczak and Cerpa (1999). Due to the learning set size, these side effects are unlikely to occur and the hidden 
Table 2b. Correlation matrices computed with three different thresholds. Same layout as in Table 2a.

\begin{tabular}{|c|c|c|c|c|c|c|c|}
\hline $330 \mathrm{~K}$ & & & & & & & \\
\hline WV_062 & 1.000 & 0.969 & 0.660 & 0.861 & 0.922 & 0.051 & 0.932 \\
\hline WV_073 & & 1.000 & 0.655 & 0.841 & 0.885 & 0.130 & 0.959 \\
\hline IR_087 & & & 1.000 & 0.727 & 0.697 & -0.417 & 0.627 \\
\hline IR_097 & & & & 1.000 & 0.937 & -0.223 & 0.884 \\
\hline IR_108 & & & & & 1.000 & -0.120 & 0.904 \\
\hline IR_120 & & & & & & 1.000 & 0.160 \\
\hline IR_134 & & & & & & & 1.000 \\
\hline \multicolumn{8}{|l|}{$273 \mathrm{~K}$} \\
\hline WV_062 & 1.000 & 0.958 & 0.262 & 0.841 & 0.909 & 0.384 & 0.914 \\
\hline WV_073 & & 1.000 & 0.188 & 0.770 & 0.835 & 0.493 & 0.942 \\
\hline IR_087 & & & 1.000 & 0.605 & 0.478 & -0.546 & 0.070 \\
\hline IR_097 & & & & 1.000 & 0.965 & 0.033 & 0.748 \\
\hline IR_108 & & & & & 1.000 & 0.178 & 0.824 \\
\hline IR_120 & & & & & & 1.000 & 0.615 \\
\hline IR_134 & & & & & & & 1.000 \\
\hline \multicolumn{8}{|l|}{$233 \mathrm{~K}$} \\
\hline WV_062 & 1.000 & 0.891 & -0.377 & 0.741 & 0.845 & 0.568 & 0.847 \\
\hline WV_073 & & 1.000 & -0.218 & 0.703 & 0.770 & 0.482 & 0.778 \\
\hline IR_087 & & & 1.000 & 0.159 & -0.022 & -0.710 & -0.464 \\
\hline IR_097 & & & & 1.000 & 0.969 & 0.127 & 0.611 \\
\hline IR_108 & & & & & 1.000 & 0.285 & 0.722 \\
\hline IR_120 & & & & & & 1.000 & 0.712 \\
\hline IR_134 & & & & & & & 1.000 \\
\hline
\end{tabular}

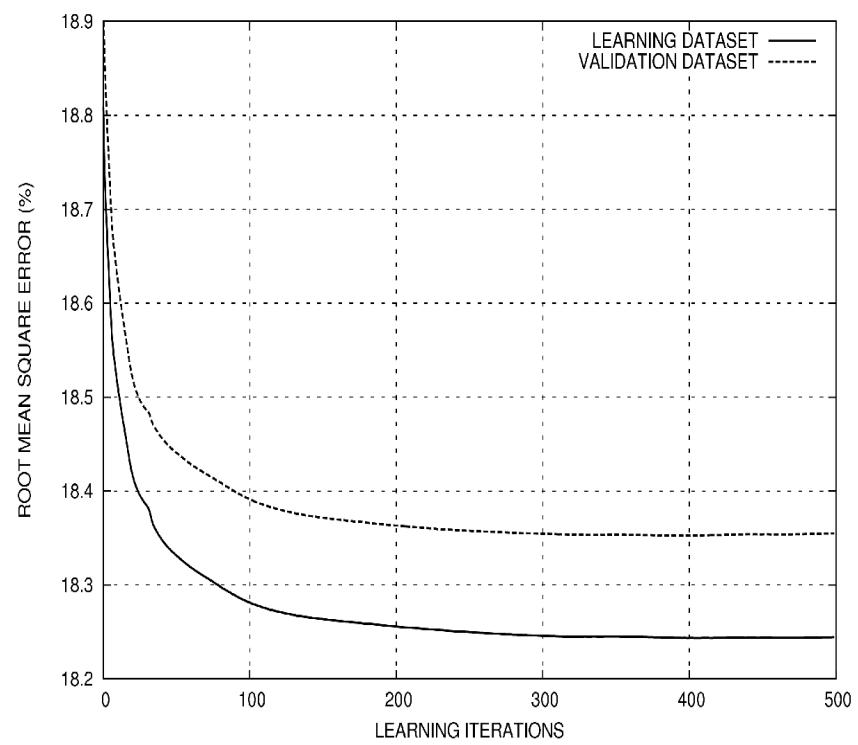

Fig. 5. RMSE is plotted against number of learning step iterations. Learning (resp. validation) dataset is plotted in plain (resp. dashed) line.

nodes number is set to twice the input nodes number.

The error back-propagation algorithm is perhaps the most widespread method to set the network coefficients (Rumel- hart et al., 1986). After a random network initialization, each element of the training set is considered in a two-step computation. An error is computed by the difference between the network estimated value and the actual rainfall occurence value. Then this error, multiplied by a decaying impact coefficient, is used to correct the network coefficient according to their relative importance in final output. This algorithm should converge on a local minimum of the error function provided it is repeated several times on the training set. As it is a step by step method the records order in the training set is not indifferent and the best results are obtained with a uniform distribution error in this set. Therefore to suppress the correlation effect linked with remote sensing image coherence, a data scrambling where records are randomly ordered is performed before training.

To assess the reliability of the neural network chosen architecture, the co-located pixels dataset has been divided into two subsets: a learning database (75\% of the cases) and a test database ( $25 \%$ of the cases). The first one is used to compute the coefficients values and the second one is dedicated to validate these coefficients with an independent dataset. The Root Mean Square Error (RMSE) between reference and estimation is calculated for all iterations of the learning phase (Fig. 5). On this graphic, the two curves are similar even if the RMSE is slightly higher for the independent validation 

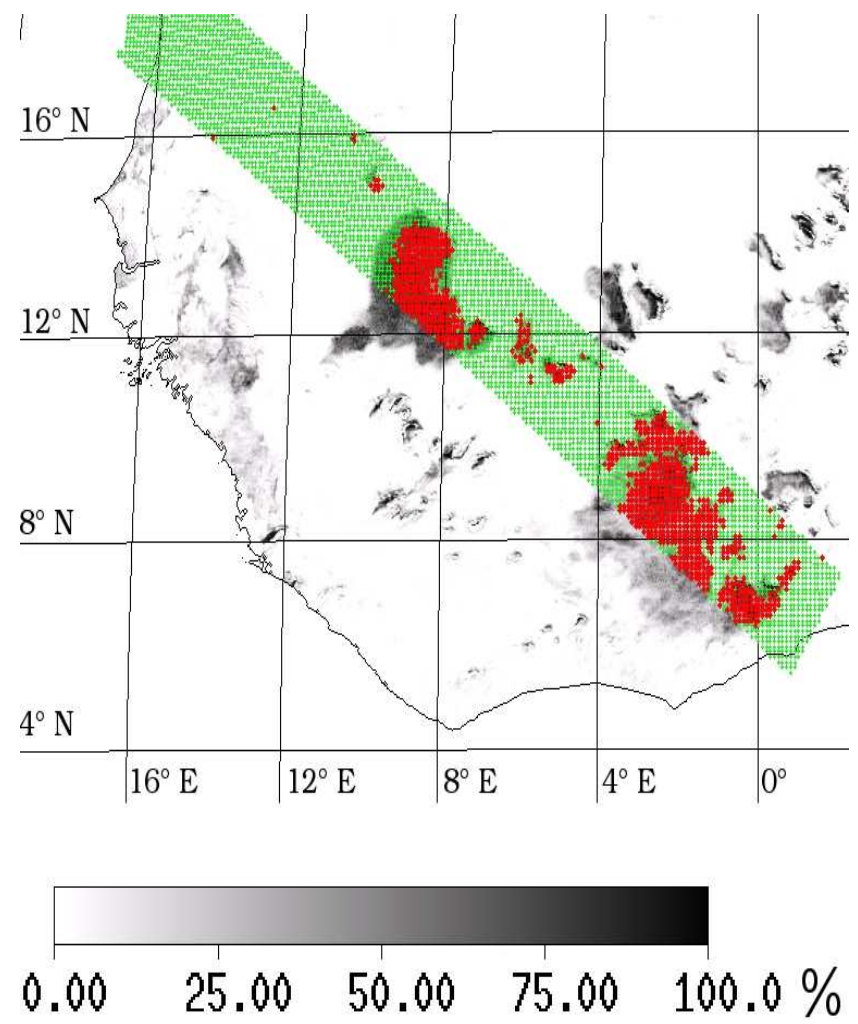

Fig. 6. EPSAT-SG rainfall probability estimate (gray scale) collocated with TRMM/PR.

dataset. The second relevant information on this graphic is that the RMSE does not increase even after 500 learning iterations suggesting that there is no over-training effect and that the neural network is properly sized. As the RMSE decreases very slowly after 200 iterations, there is no interest in using more iterations. Finally, the RMSE for the learning dataset is about $18.25 \%$ and only $0.10 \%$ higher for the validation one. This RMSE value represents the uncertainty of the rainfall probability mean value.

Applying the resulting neural network coefficients to every MSG pixels of the studied area, instantaneous rainfall probability images are provided with the MSG time and space resolutions. In Fig. 6 an estimated rainfall probability field (in gray tones) is superimposed with a coincident TRMM/PR track where rainy pixels are plotted in red and non-rainy in green. The active cells appear as clearly delineated by the rainfall probabilities. On this situation the main features of the precipitation field as detected by TRMM/PR are properly reproduced by the neural network output.

In order to assess to which extent the estimated rainfall probability is environment specific, four learning sets have been extracted on the AMMA area for 2004 and 2006. Two monsoon pre-onset datasets from 1 May to 30 June and two monsoon post-onset datasets from the 15 July to 15 September. On each learning set a neural model has been fitted with
Table 3. Neural network estimation errors on different dataset (columns) versus training set (rows).

\begin{tabular}{lcccc}
\hline & 2004-mj & 2004-jas & 2006-mj & 2006-jas \\
\hline 2004-mj & 0.002889 & 0.004416 & 0.003016 & 0.004986 \\
2004-jas & 0.002895 & 0.004342 & 0.003027 & 0.004923 \\
2006-mj & 0.002957 & 0.004518 & 0.002975 & 0.005012 \\
2006-jas & 0.002995 & 0.004421 & 0.002964 & 0.004871 \\
\hline
\end{tabular}

22 hidden nodes, then the mean quadratic error of this model has been computed for all the learning sets. The results are summarized in Table 3 where the lines are indexed by the estimated models and the columns by the learning sets. The interpretation of the matrix diagonal is slightly different as it represents a model bias and not an estimation bias. Nevertheless the results look as consistent: the values are more homogeneous among columns than among lines. This should suggest that an estimated network shows very similar performances on different periods and there is no real benefit to expect in retraining the network once is has been estimated on a significant dataset. The main error should be much more dependent on the meteorological phenomena distribution which could explain the inter columns variation. It can be noticed that the columns smaller values are, except one, on the main diagonal. As expected the method performs better when using actual data rather than a previous estimation, but this advantage is minor and in one situation the estimation local minimum has been out performed by an other model.

As suggested by these results, the relationship between infrared brightness temperatures and precipitation cannot be improved by a simple temporal or spatial stratification. This hypothesis is confirmed by the classification carried out on the global dataset. This dataset has been split in two periods (May to July and August to October) and according to a $2.5^{\circ}$ regular grid. On each box an empirical rainfall probability function is computed. For a statistical stability reason only one channel $(10.8 \mu \mathrm{m})$ is considered and the boxes with less than 3000 rainfall detections are discarded. Then a non-supervised classification in four clusters is performed for each period. This classification is based on a K-means algorithm: a number of clusters is set, then an iterative process splits the dataset in oder to minimize the intra-cluster variances. The variance computation relies on a simple $\mathrm{Eu}-$ clidian distance. This classification is purely statistical and does not integrate any input based on aerologic parameters, nevertheless it could be expected that some of the main climatic zones would match with generated classes. Figure 7 a (resp. 8a) displays the four class centers and Fig. 7b (resp. $8 b)$ the spatial class repartition. At a first glance the center class distribution are differentiated by their kurtosis, from a quasi linear relation (green curve) to a relation looking as a power law (purple curve). But even these two classes do not show any regularity in their spatial distribution and are 


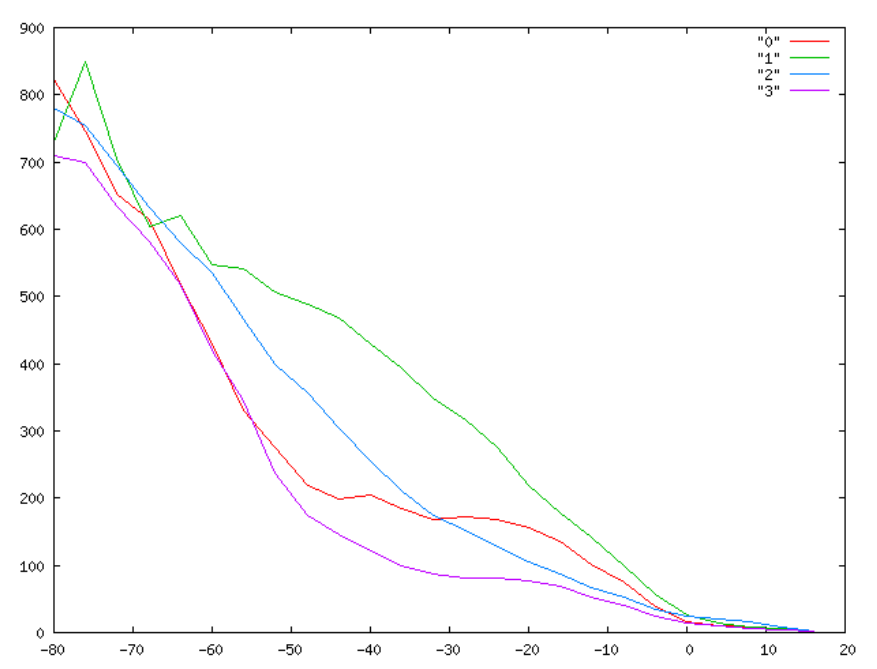

Fig. 7a. Pre-onset period: mean probability function for classes 0 , $1,2,3$. Temperature is coded in degree $\mathrm{C}$.

deeply different from one period to an other. None of the synoptic scale atmospheric phenomena or agro-climatic zones can be identified on the classifications. The only identifiable pattern is the quasi-linear class (green code) which is in some extent associated with mountainous area. Precipitation enhancement linked with relief and elevation is well known but this observation is slightly different: when orographic effects are predominant, cloudiness could not be used as a proxy for rainfall as the empirical relationship itself appears as orography dependent. But despite this local effect which should be confirmed by further studies, these observations suggest that using these boxes as a stratification basis would not enhance the estimation sensitivity but would only reduce the sample size.

\section{Rainfall potential intensity}

As written in Sect. 3, the EPSAT-SG rainfall estimate $\left(R_{\text {Est }}\right)$ is the product of the Rainfall Probabilities $\left(R_{\text {Prob }}\right)$, by rainfall potential intensity $\left(R_{\text {PotInt }}\right)$ maps:

$R_{\text {Est }}=R_{\text {Prob }} x R_{\text {potint }}$

where $R_{\text {Est }}, R_{\text {Prob }}$ and $R_{\text {PotInt }}$ are functions defined in space and time.

The rainfall potential intensity (noted RPI below) is estimated by a downscaling method which is a way to include small scale variability extracted from geostationary sensors. The Rainfall Probability can be computed with the time and space resolution of GEO satellite which is far smaller than the statistical validity scale of any rainfall estimation product. But assuming selection of a rainfall reference product

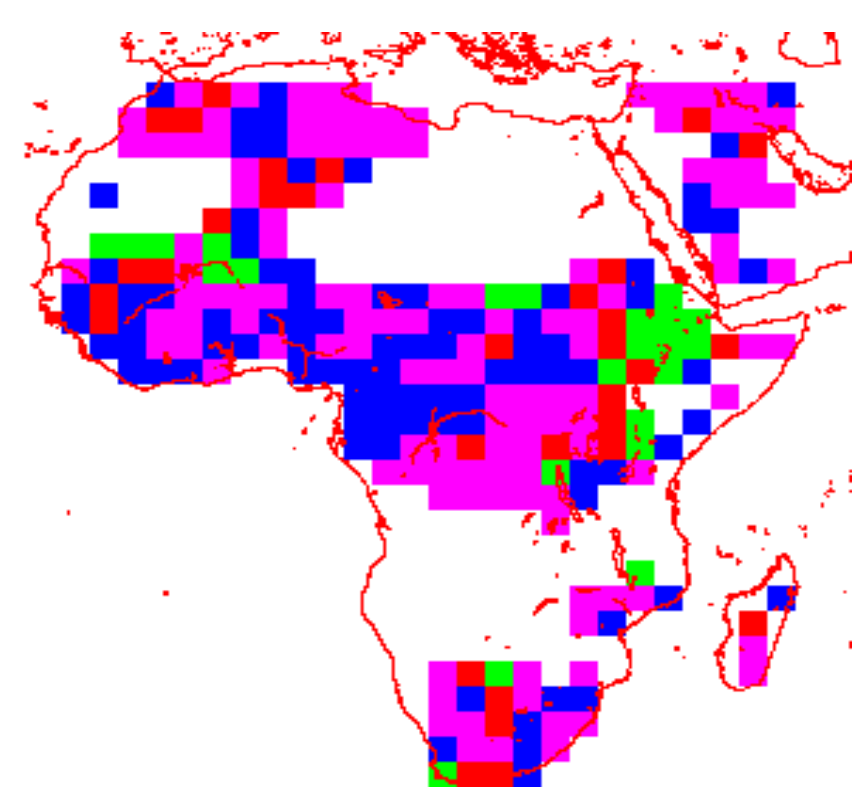

Fig. 7b. Pre-onset period: Spatial repartition of the four classes computed by non supervised classification. Same color code as in Fig. 7a.

and an associated space-time validity domain size, RPI can be estimated by the formula:

$R_{\text {PotInt }}(B)=\int_{B} R_{\text {ref }} / \int_{B} R_{\text {Prob }}$

where $B$ is a spatio-temporal domain whose sizing is important for final product accuracy and $R_{\text {ref }}$ an accumulated rainfall field which is intermittent and/or defined at a coarser scale. It has to be noticed that $B$ is not necessarily a regular box and should the rainfall reference be extracted from LEO microwave data, $B$ would be a time buffer around the satellite swath inside a surrounding box. The issue is to derive RPI at the fine satellite resolution scale from RPI on the integration domain $B$. A simple non overlapping set of domains could be considered and a RPI constant value computed for each element of this set. But such a process would produce rough boundary effect when downscaling. To avoid this effect, $B$ will be defined as a three-dimensional slide window. The Eq. (2) is then used to compute RPI on the center of the box which is defined as identical to $R_{\text {PotInt }}(B)$.

Setting the size of this slide window is mainly a statistical issue, the larger this size the greater the influence of rainfall probability field. Obviously a window size identical to the resolution of $R_{\text {PotInt }}$ would produce a $R_{\text {Est }}$ field identical to $R_{\text {ref }}$ field. For the implementation of EPSAT-SG in AMMA database, some operational considerations have lead to select the GPCP product as the reference accumulated rainfall field. The window size has been set according to Richard and Arkin (1981) which state that the maximum of correlation between cold cloud duration and precipitation occurs for a window of one month by $2.5^{\circ}$ in latitude and longitude. 


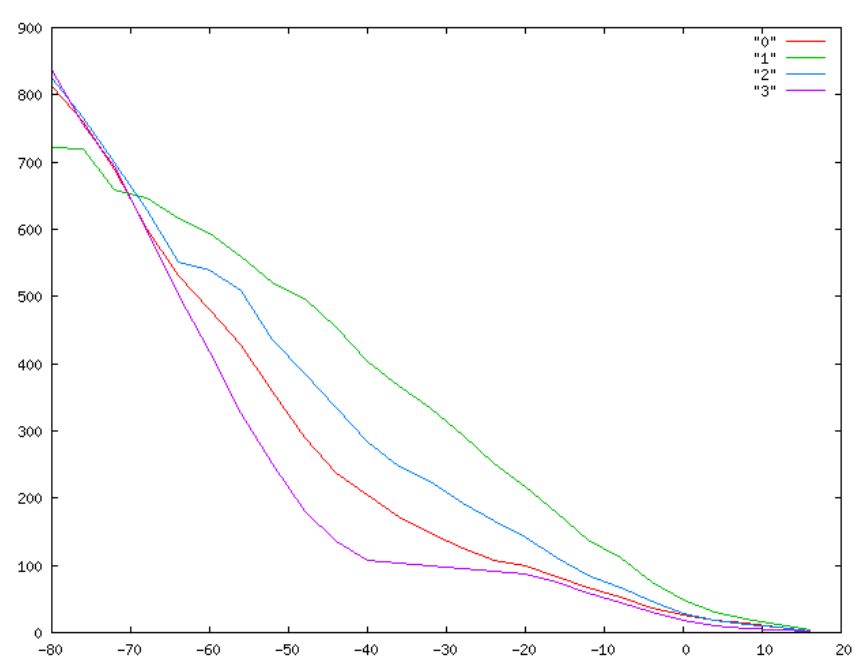

Fig. 8a. Post-onset period: mean probability function for class 0 , 1,2 and 3. Although this classification is independent from the previous one, color code is selected to get maximum similarity with Fig. 7a. Temperature is coded in degree $\mathrm{C}$.

This choice is conservative and a more sophisticated implementation would have to deal with a window size which is dependent on an estimation error.

Among the GPCP products the daily $1^{\circ}$ grid has been extracted and interpolated at the scale of the MSG pixel to constitute the $R_{\text {ref }}$ fields. The Eq. (3) is then the discrete translation of Eq. (2):

$$
R_{\text {PotInt }}=\alpha \times \frac{\sum_{31 \text { Days }}\left(\sum_{2.5 \text { deg res }} R_{\text {ref }}\right)}{\sum_{31 \text { Days }}\left(\sum_{2.5 \text { deg res }} R_{\text {Prob }}\right)}
$$

where $\alpha$ is a correction coefficient set to counterbalance missing slots. From Eq. (3) a daily image of PRI is computed at the GEO satellite spatial resolution. According to this equation, $R_{\text {PotInt }}$ images are the results of a 31-day rainfall accumulation (in millimeters) divided by a rainfall duration as expressed by the accumulated rainfall probability.

Equation (1) can be presented as an extension of the GPI (Arkin, 1979). But, whereas the rainfall probability part is only represented by a simple threshold, which provides $0 \%$ or $100 \%$ probabilities in the GPI method, the values of the rainfall probability maps calculated by the feed forward neural network are varying from $0 \%$ to $100 \%$. In a same way, the $3 \mathrm{~mm} / \mathrm{h}$ rain rate value proposed by Arkin could be applied, but the rainfall efficiency obviously is changing in accordance with the geographic situation or the season. Rainy events on the Guinean Coast are much more frequent, but less intense than those which occur in the Sahelian region. Moreover, with the latitudinal gradient of humidity, the evaporation phenomenon below clouds is more important in the

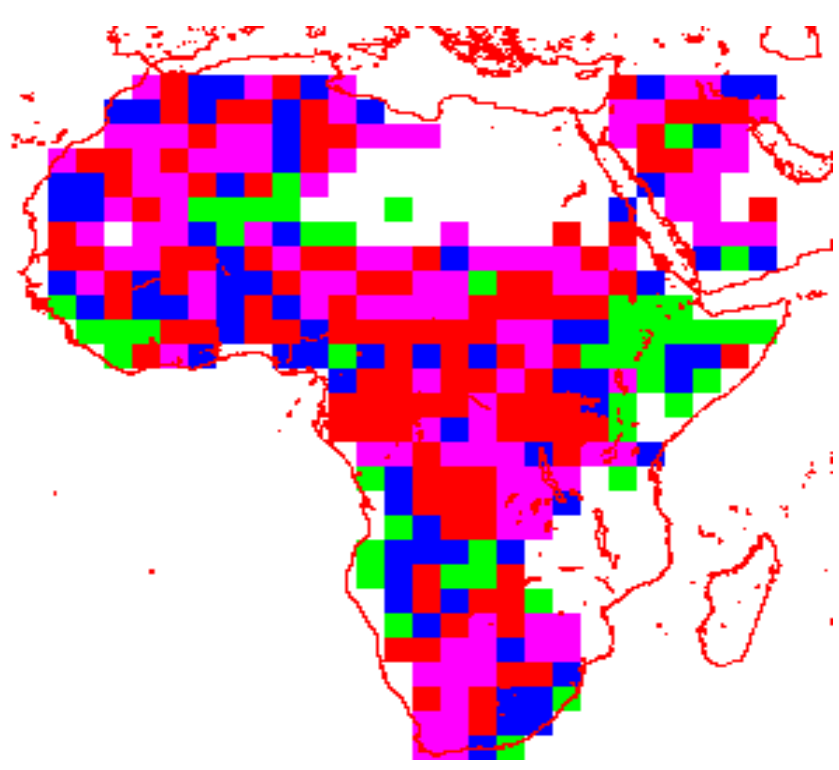

Fig. 8b. Post-onset period: Spatial repartition of the four classes computed by non supervised classification. Same color code as in Fig. 8a.

Sahelian region than close to the South coast. For all these reasons, it seems more appropriate to use a rainfall potential intensity value, which is varying in time and space, rather than a constant rain rate value.

Figures 9 to 12 present four daily 2006 PRI images computed by different methods. The rain rates are expressed in millimeters per hour and it can be noticed that for all figures the PRI falls in a range of 0 to $6 \mathrm{~mm} / \mathrm{h}$. Those values are close to the GPI rain rate $(3 \mathrm{~mm} / \mathrm{h})$. However, the fact that there is a maximum value of $6 \mathrm{~mm} / \mathrm{h}$ is one of the limitations of the EPSAT-SG method: high precipitation rates and short-time rainfall events cannot be properly retrieved with this algorithm. This weakness is encountered in many methods based on geostationary satellite IR data. For some part it is linked to the low frequency of high intensity event and thus to the difficulty to retrieve them from a statistical process. But it can be mainly related to the indirect nature of the measurement. The neural network inputs are thermal infrared brightness temperatures and therefore inform about cloud canopy properties and not about intense precipitation location as indicated by radar data. The thermal infrared information appears as smoothed compared with microwave information. In some extent the rainfall probability downscales the GPCP information but fails to render fine scale structures and thus attenuate the highest rainfall intensities.

Figure 10 is computed according to Eq. (3). A sliding space window is applied with a shift of one MSG pixel. Each obtained value of the right side of the Eq. (3) is set to the central position of the 2.5 degrees integration area. Therefore the integration zone is a disc of 42 pixels radius corresponding nearly to a 2.5 degrees diameter. Then, the sliding windows 

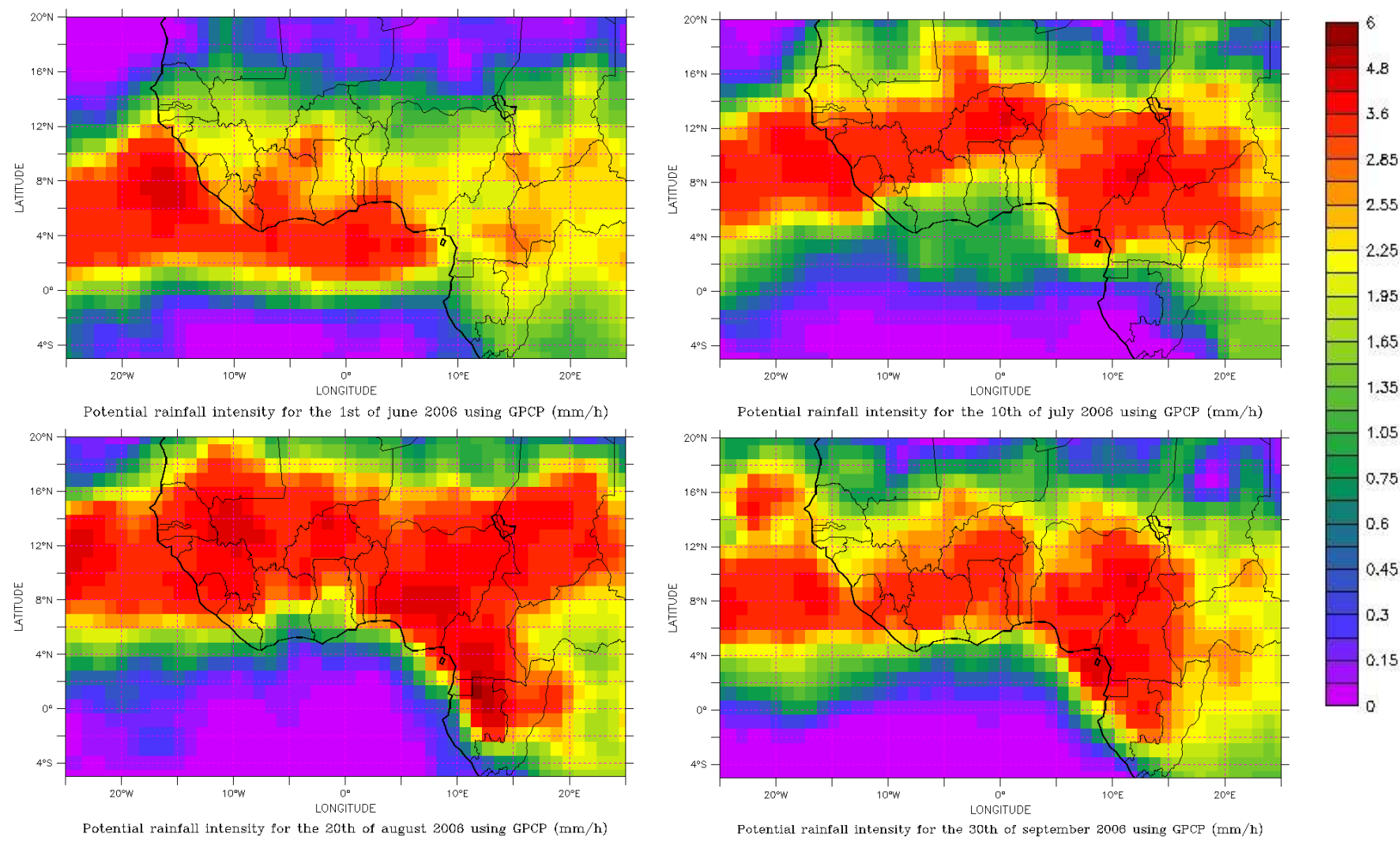

Fig. 9. Rainfall potential intensity maps computed without spatial integration window.

are applied in time and space and the final RPI products are provided with the time resolution of the reference dataset (1 day with GPCP-1dd) and the space resolution of the geostationary satellite ( $3 \mathrm{~km}$ for MSG). On the contrary Fig. 9 is computed without spatial integration. A comparison of these two figures demonstrates clearly the benefits of using a spatial integration area. On one hand the artifacts created by $1^{\circ}$ grid boundaries disappear. On the other hand some physical discontinuities are better delineated. On the 1 June 2006 the Guinean shoreline effect appears more clearly in Fig. 10a than in Fig. 9a.

The Inter Tropical Convergence Zone (ITCZ) evolution can be clearly observed consistently with the season: on Fig. 10a the largest values are located over ocean just on south of the Guinean coast and these values are going northward during the rainy season (July and August) before going back southward in September.

Integrating this method in an operational environment raises the issue of producing a temporary rainfall estimator if the GPCP data are not available in due-time. In order to assess the impact of using a climatology instead of actual data, Fig. 11 is computed replacing 2006 GPCP data with an 8 -year climatology (1997 to 2005).
When comparing Fig. 10 and Fig. 11, similar patterns appear with very comparable values. There is an exception concerning the 30 September 2006 (Figs. 10d and 11d). This difference is due to a very late rainy season over West Africa in 2006, which cannot be satisfactorily reflected by the climatology. But the values remain stable with a maximum close to $6 \mathrm{~mm} / \mathrm{h}$. Anyway the rainfall probabilities correspond to the 2006 rainy season situation and cloud trajectories and not to the climatology. This feature makes the images presented on Fig. 11 patchier than those on Fig. 10. Although integrating directly a rainfall climatology could produce some provisional results it appears much more appropriate to use a PRI climatology computed on coincident rainfall probabilities and rainfall reference intensities.

An other way to reduce the product delivery delay would be to select a reference rainfall data-source based on passive microwave from LEO satellites. Contrary to the GPCP which is highly dependent on rain-gauges data, this data-source is available in near real-time. To test this alternative a PRI (Fig. 12) is computed from the 3B42 product which is mainly calibrated by passive microwave data.

Several remarks arise from the comparison between Figs. 10 and 12. First of all, RPI have again the same range from 0 to $6 \mathrm{~mm} / \mathrm{h}$ which reinforces the idea of stability of this 

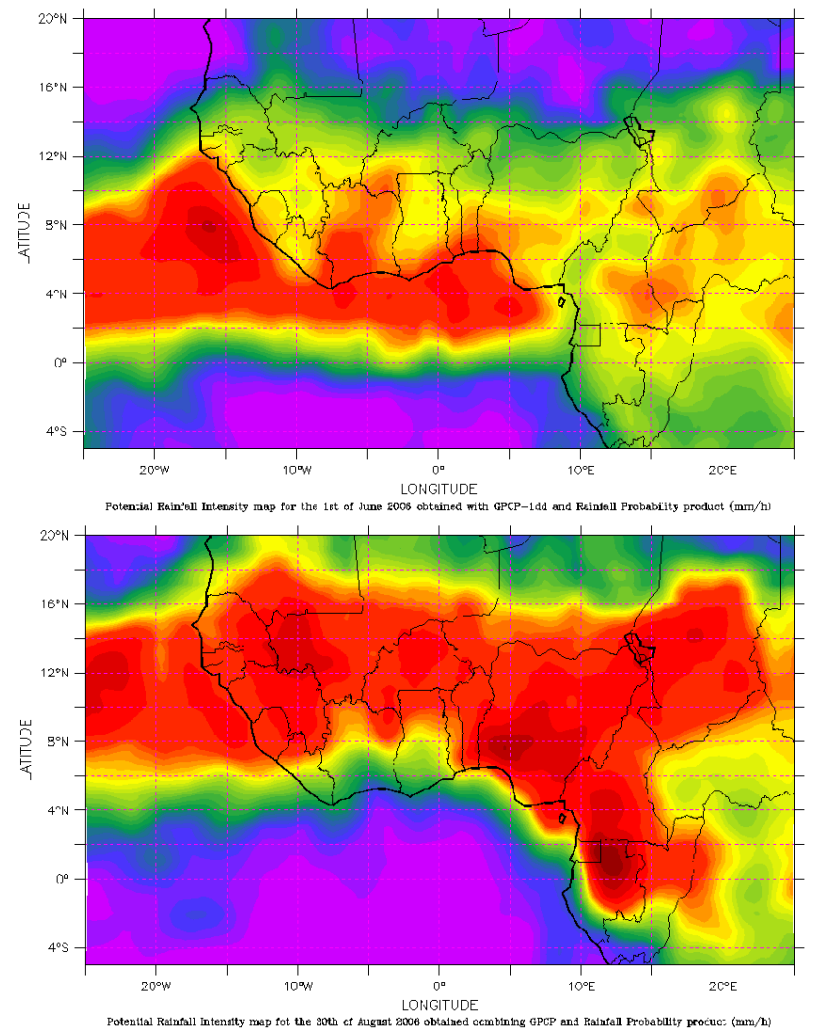

Fig. 10. EPSAT-SG daily rainfall potential intensity.

product. Moreover, the RPI values are still increasing in the ITCZ and large climatic regions have more or less the same values. However, if the RPI were very smooth with GPCP$1 \mathrm{dd}$ they are not with 3B42. This is due to the nature of the respective reference datasets. The GPCP-1dd estimates are conditioned by geostationary information and ground network which deliver time continuous data series. By contrast the 3B42 estimator depends highly on the LEO satellite coverage and is greatly influenced by the microwave estimated rain rates used as input. The related risk is to overestimate locally rainfall estimates causing the apparition of high value spots on RPI maps. The spot positions depend on the colocalization of LEO satellite data and rainy events during the period of study, which is unpredictable. The simple integration frame proposed for AMMA implementation appears as more adapted to GPCP than to 3B42. Integrating a microwave only product should likely require a more complex sliding window design associated to an along track product rather than to a gridded product. But this should also make the implementation much more complex.

\section{Estimated rainfall}

A Rainfall Probability Intensity $\left(R_{\text {Potint }}\right)$ can be interpreted as the mean rate of a daily rain event and a Rainfall Proba-

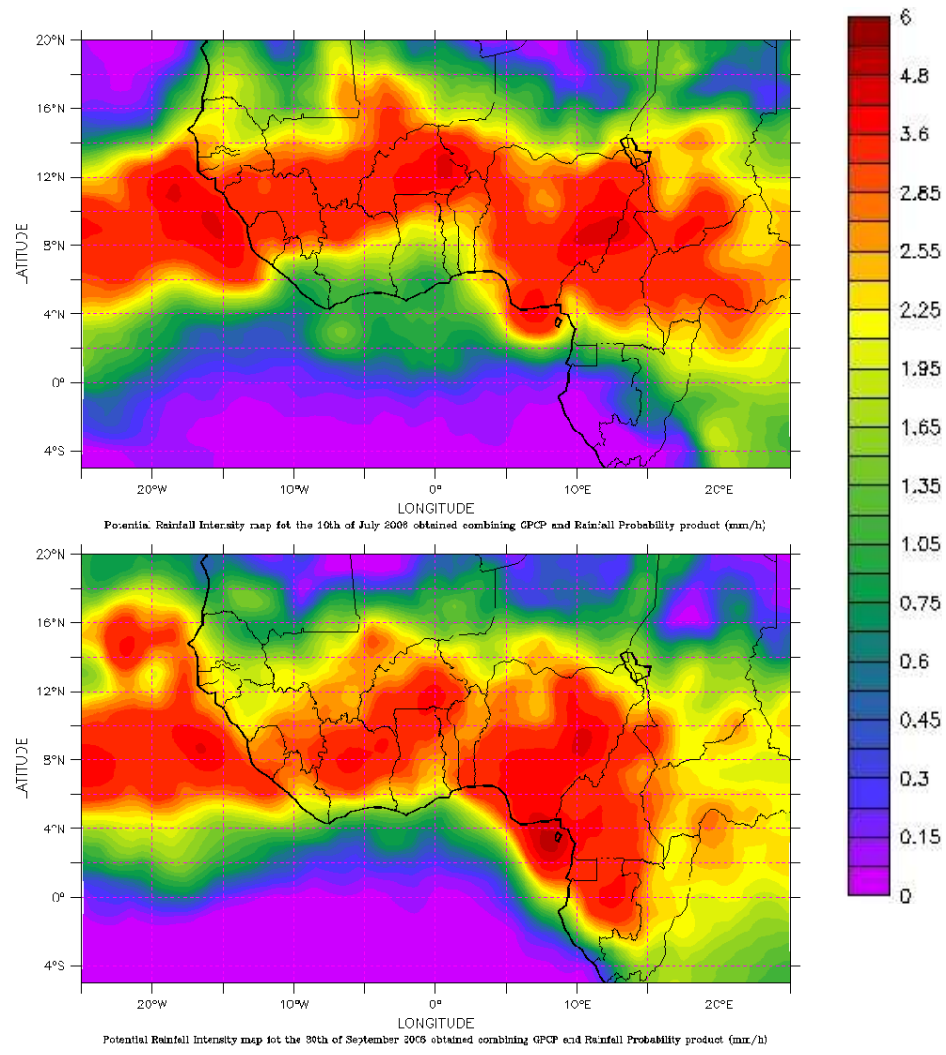

bility $\left(R_{\text {Prob }}\right)$ as the duration of this event. As a single RPI is computed for the AMMA implementation, computation of accumulated rainfall is rather straightforward. Once the RPI maps are computed, the estimated rainfall estimates $\left(R_{\text {Est }}\right)$ can be obtained with the space and time resolution of MSG. At time $t$ during day $d$ and pixel $a$ the $R_{\text {Est }}$ value can be derived from Eq. (1) as follows:

$R_{\text {Est }}(a, t)=R_{\text {Prob }}(a, t) \times R_{\text {PotInt }}(a, d)$

Rainfall estimates are obtained with MSG time and space resolution. However, as this method is mainly based on geostationary satellite data, final estimates have to be integrated in time and space in order to limit the estimation bias. The principal interest of this fine time and space resolution is its flexibility for the users. It can be integrated in time and space to fit with products of any other scales or boundaries like a daily period starting at $6 \mathrm{a} . \mathrm{m}$. or like a specific watershed.

The estimated rainfall accumulation during a period $T$ can be easily computed by the following formula:

$R_{\mathrm{Est}}(a, T)=\frac{1}{\alpha} \sum_{t \hat{I} T} R_{\mathrm{Est}}(a, t)$

where the coefficient $\alpha$ is the same the one in Eq. (3). Indeed, the fact that there are missing probability images leads to an 

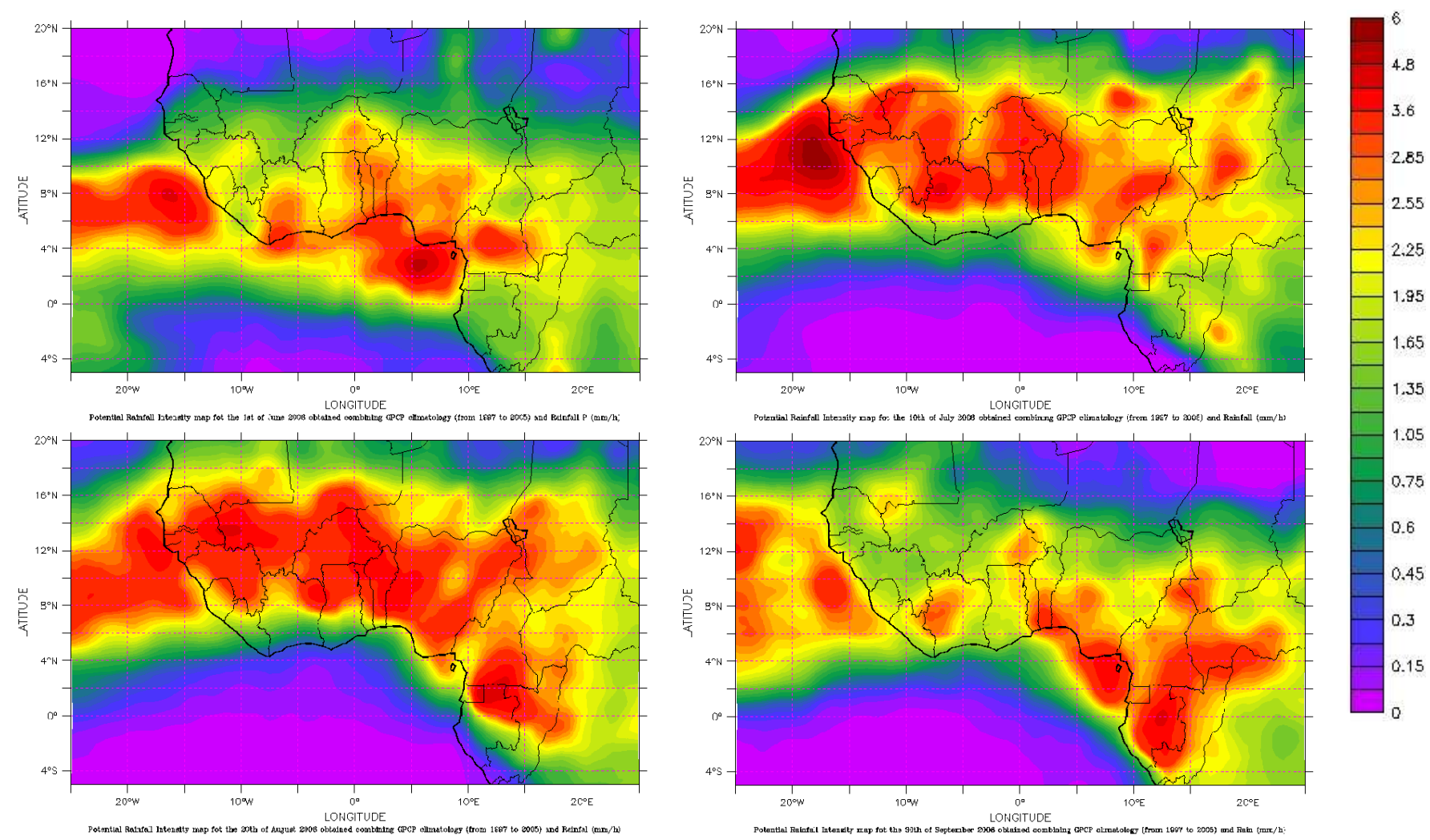

Fig. 11. EPSAT-SG rainfall potential intensity computed with a 8-year climatology instead of actual data.

underestimation of rainfall amounts and a correction coefficient is necessary to extend the total rainfall amounts to the whole studied period $T$.

Figure 13 represents EPSAT-SG (Fig. 13a) and GPCP-1dd (Fig. 13b) rainfall accumulation estimates for the 10 July 2006. High rainfall patterns can be seen on the west coast of Guinea and Sierra Leone, over the border between Burkina and Mali and over South Chad. North of $14^{\circ} \mathrm{N}$, rainy events are quite inexistent which is in accordance with the Sahelian climatology. The maximum daily accumulated precipitation of $40 \mathrm{~mm}$ is realistic too. The fine structure of convective clouds is clearly apparent on Fig. 13a. Most of the patterns can be observed on both images. More details can be observed on EPSAT-SG estimates and they are also some differences such as the pattern seen over East-Mali. As the only available ground data are the synoptic stations distributed through the Global Telecommunication System it is difficult to assess the relative accuracy of these two products. Two synoptic stations, Nara and Nioro-Sahel, are located on the area of the raining spot detected by EPSAT-SG but none of these two stations reported any data. The only ground information can be extracted from Mauritanian Nema station which is on the periphery of this spot. The reported $24 \mathrm{~h}$ accumulation of $5 \mathrm{~mm}$ on the 11 July 2006 morning should be more consistent with EPSAT-SG estimation than with GPCP- 1dd. The discussion highlights the difficulty of fine product inter-comparison based on scarce network.

When the EPSAT-SG estimates are gridded by $1^{\circ}$ to fit with the GPCP space resolution (Fig. 13c) some lower values of the rainfall amounts can be observed when compared with the GPCP estimates on Fig. 13b. This is due to the smoothing effect induced by the downscaling formula presented in Eq. (2). It can be noticed that the main differences occur in coastal and mountainous area where the spatial gradient of precipitation is strong and therefore the smoothed gridded precipitation fields are inaccurate.

To point the differences between rainfall probability and rainfall estimation products, both of them have been represented. Figure 14a shows the mean rainfall probability during August 2006 and Fig. 14b corresponds to the rainfall amount during the same period. These two images contain similar patterns as it could be expected from the method concept. This similarity can be observed around the west coast. However, there are some differences over Guinea and Nigeria where rain accumulations are higher than it could be anticipated from the rainfall probability. On the contrary, above $16^{\circ} \mathrm{N}$, rainfall accumulations seem to be less important than expected. 

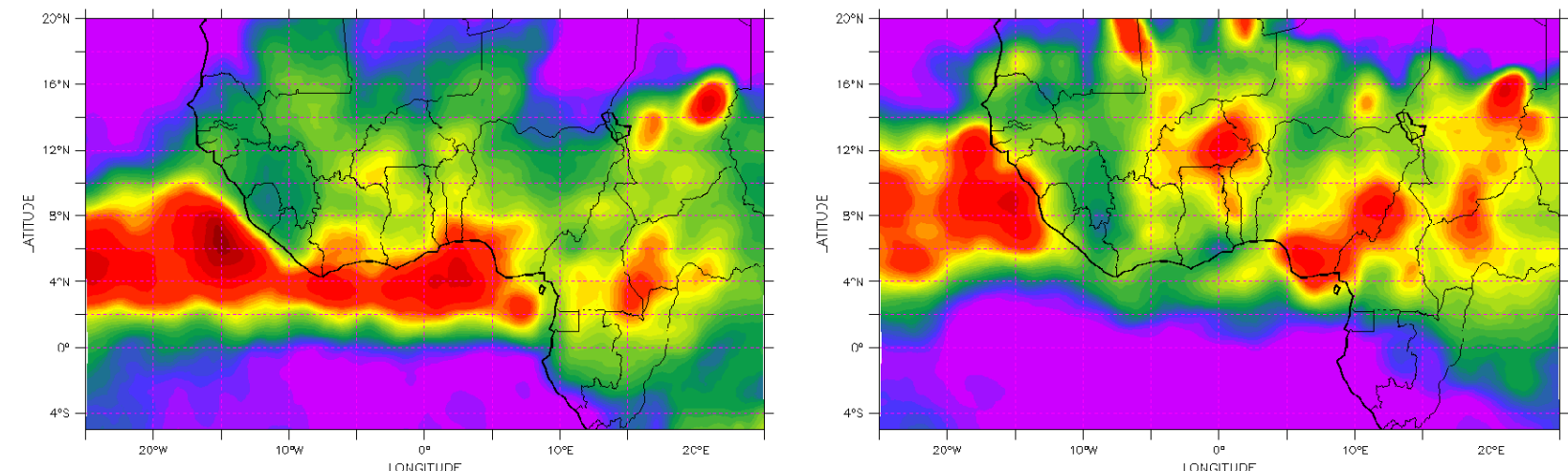

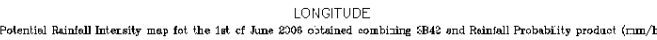
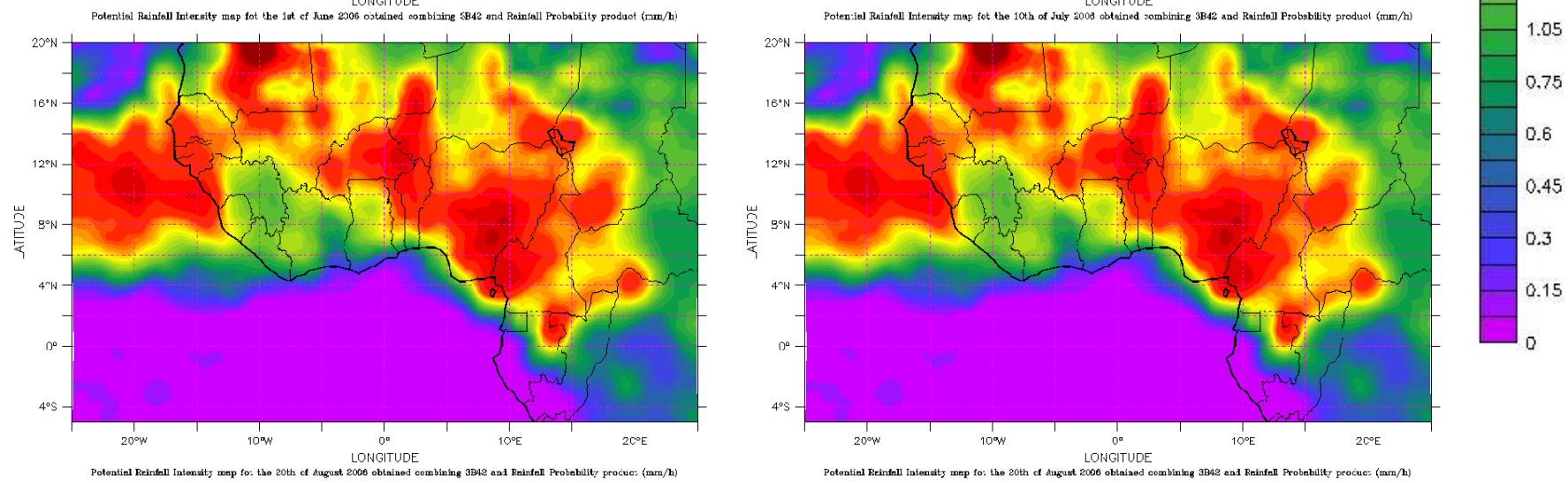

Fig. 12. EPSAT-SG daily rainfall potential intensity maps computed with 3B42 product instead of GPCP-1dd.

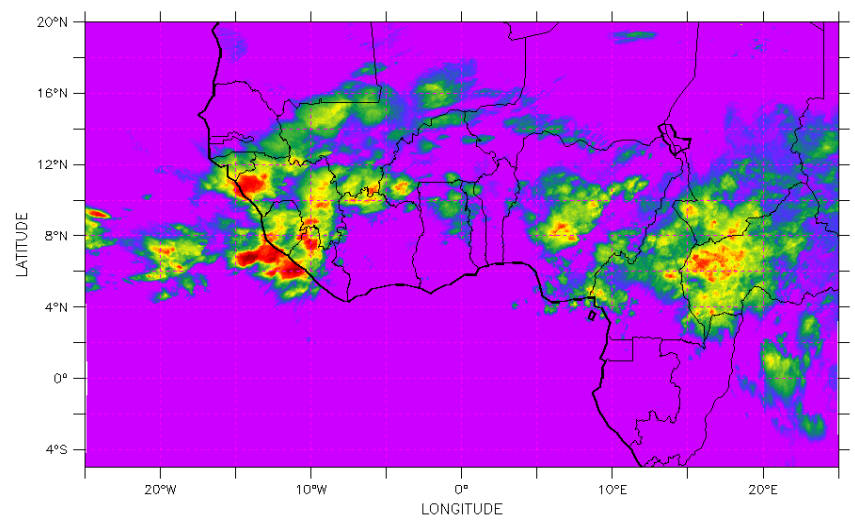

Daily rainfall EPSAT-SG accumulation for the 10th of July $2006(\mathrm{~mm})$

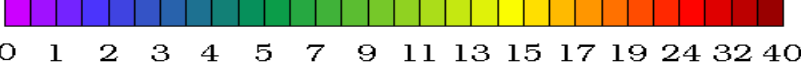

Fig. 13a. Daily cumulated EPSAT-SG rainfall estimation.

\section{Validation}

When validating a downscaling method a first issue is to assess the positive impact on the downscaled information itself. This validation exercise has been performed for the Sahelian

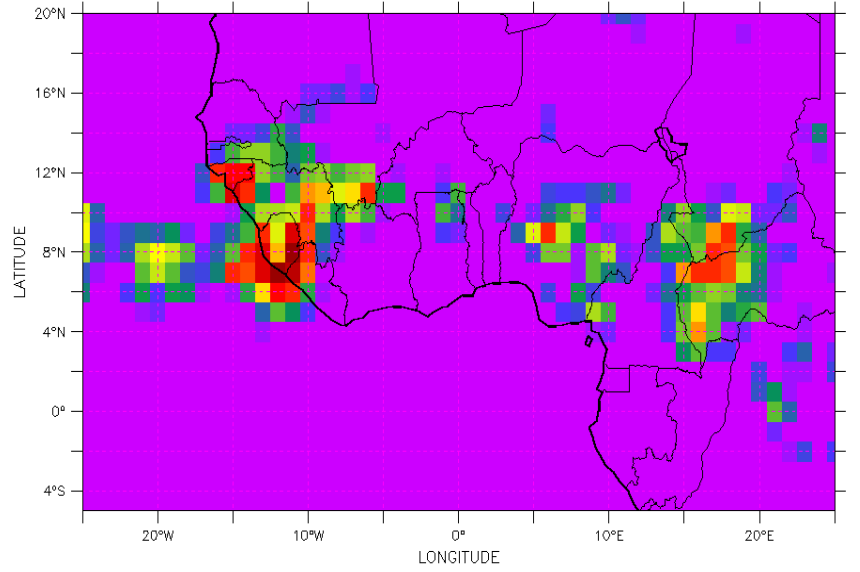

Daily rainfall GPCP-1dd accumulation for the 10 th of July $2006(\mathrm{~mm})$

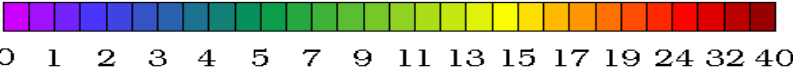

Fig. 13b. GPCP-1dd rainfall estimation.

region in West Africa during the 2004 rainy season. A raingauge network is managed by the CILSS organism (Comité permanent Inter-états de Lutte contre la Sècheresse au Sahel) 

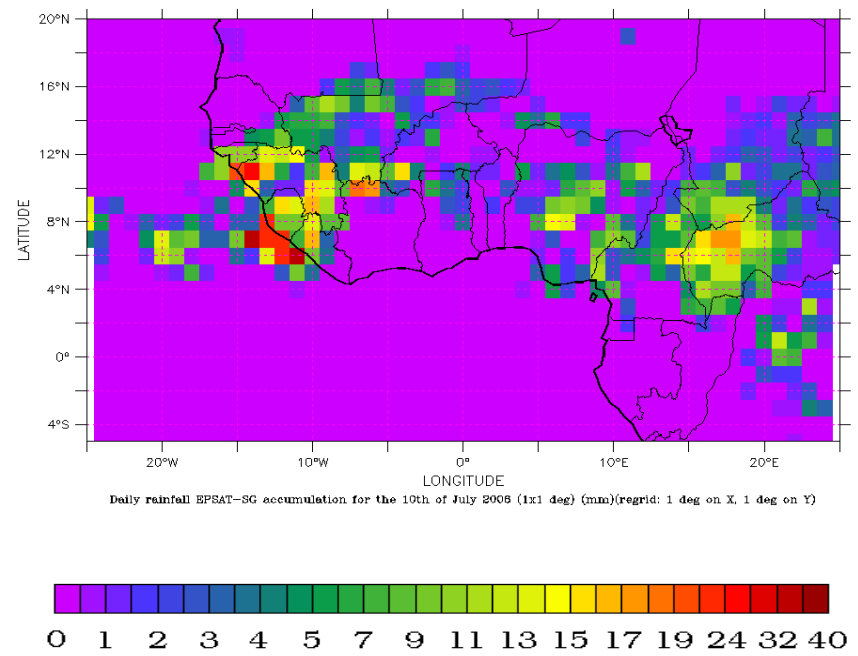

Fig. 13c. Daily cumulated EPSAT-SG on a $1^{\circ}$ grid.

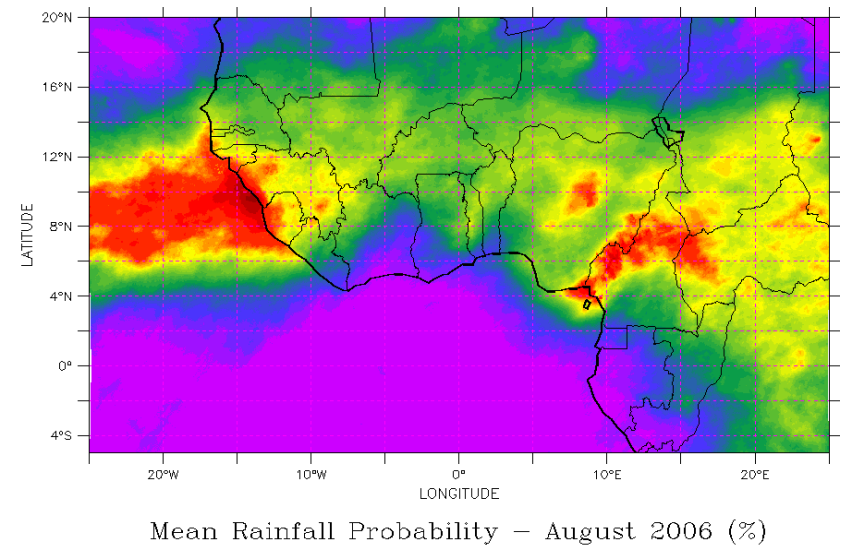

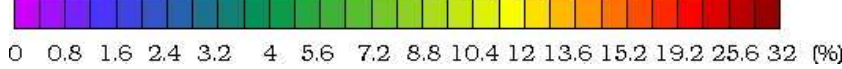

Fig. 14a. EPSAT-SG rainfall probability field for August 2006.

which concentrates data from nine different countries (Burkina Faso, Cap-Verde, Gambia, Guinea Bissau, Mali, Mauritania, Niger, Senegal and Chad). The data have been obtained from AGRHYMET as kriged fields on 10-day periods with 0.5 and 1 degree space resolution. The kriging method is described in Ali et al. (2005) and an associated estimation error of the rainfall amount is provided for each grid box. This network gathers about 645 stations including 75 synoptic stations which transmit their data through GTS (Global Telecommunication System). Because GPCP integrates the GTS transmitted data in the product, the synoptic stations have been excluded from the computation of the kriged maps in order to guarantee the independence between estimation data and validation data. Figure 15 represents the CILSS area and the CILSS and synoptic rain-gauges positions.

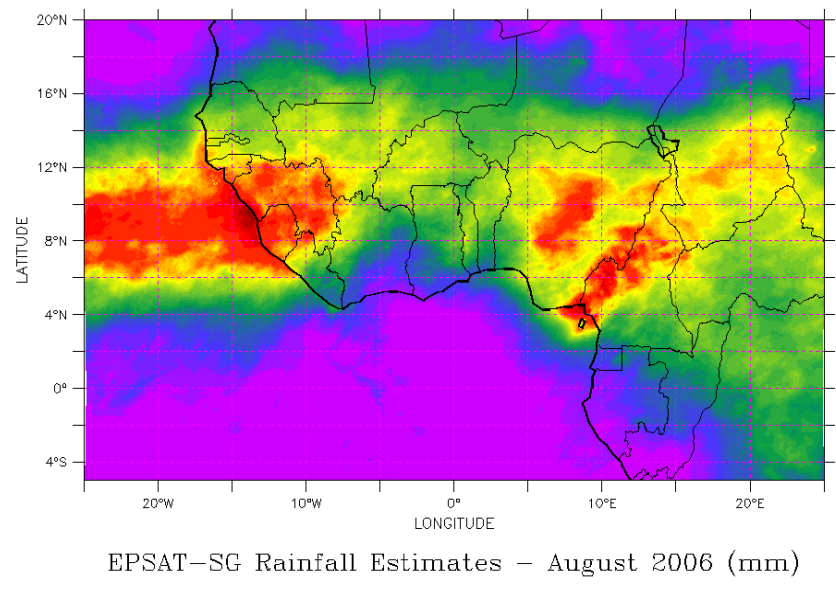

0 $20 \quad 40 \quad 60 \quad 80 \quad 100140180220260300340380480 \quad 640800$ (mm)

Fig. 14b. EPSAT-SG accumulated rainfall field for August 2006.

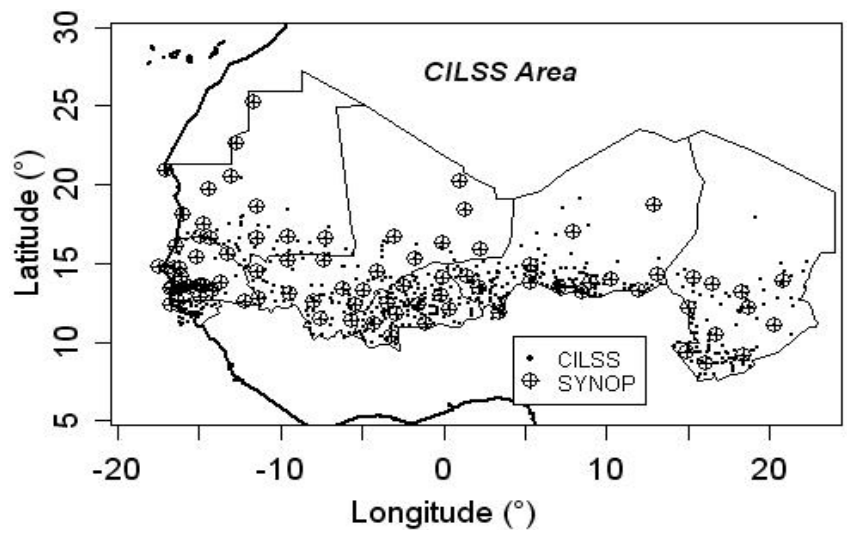

Fig. 15. CILSS synoptic and climatic rain-gauges (Ali et al., 2005).

The statistical parameters used to validate these results are the Bias, the Root Mean Square Difference (RMSD), the Skill Score Index, and the explained variance, $R^{2}$. The Bias represents the mean error produced by the algorithm according to the validation dataset while the RMSD is the average distance between estimation and its corresponding reference in a grid cell. The $R^{2}$ expresses the degree of agreement between the estimated rainfall accumulation and the reference ones. The Skill Score Index is equal to 1 if estimation and reference match perfectly and is equal to 0 if the estimation is obtained by random distribution. The interest of the skill index is to deal with the assymetric distribution of the estimated variable.

Because of the spatial heterogeneity of the rain-gauge network managed by AGRHYMET, a first study has been performed during the 2004 rainy season in order to assess the effect on validation of grid cells having few or zero rain-gauges. Table 4 summarizes the validation statistic 
Table 4. EPSAT-SG validation statistic parameters for three datasets with different minimum number of rain-gauges per gridcell.

\begin{tabular}{lccccc}
\hline & Bias & rmsd & $R^{2}$ & skill & n.cells \\
\hline All cells & 4.6 & 20.9 & 0.67 & 0.64 & 14400 \\
1 gauge & 5.5 & 17.3 & 0.73 & 0.70 & 2787 \\
2 gauges & 4.8 & 17.2 & 0.73 & 0.71 & 899 \\
\hline
\end{tabular}

parameters with best scores written in bold style, for the full dataset and two subsets. These subsets group only grid cells with a minimum of 1 or 2 embedded raingauges . The total number of grid cells is 14400 but only less than $20 \%$ have at least one rain gauge, and about $6 \%$ have a minimum of 2 raingauges. The bias does change significantly when computed on grid cells with 0,1 or 2 minimum raingauges. However it appears clearly that the RMSD, $R^{2}$ and Skill score index values are improving when the minimum number of rain-gauges per grid cells increases. However it has been checked that the improvement is really small when the minimum number is 3 instead of 2.

To improve the reliability of this validation exercise, only grid cells with at least 1 rain-gauge are taken into account. This validation is done for 10-day periods, as validation data are only available at this time resolution. The comparison has been made with a space resolution of 0.5 degree in order to get enough grid cells to be statistically significant. So the GPCP-1dd has been interpolated to this final space resolution.

The validation statistical parameters are presented in Table 5 for EPSAT-SG and GPCP-1dd; they have been computed on a set of 2787 grid cells containing at least one raingauge. EPSAT-SG estimates look better than GPCP-1dd for all the criteria. EPSAT-SG gets smaller RMSD value and higher $R^{2}(0.73)$ and Skill Score index value (0.79) than the GPCP-1dd reference dataset (respectively 0.57 and 0.42 ).

Scatter plots comparing GPCP-1dd or EPSAT-SG with rain-gauge kriged data are represented on Fig. 16. As it could be expected the regression line shows that the two products underestimate high precipitations and overestimate low ones. However the EPSAT-SG scatter plot (Fig. 16b) appears as more concentrated around the diagonal than the GPCP scatter plot (Fig. 16a). Even upscaled to match with the resolution of the rainfall reference product, EPSAT-SG performs better than GPCP-1dd. It is obvious that EPSAT-SG is bound to GPCP-1dd by construction; the correlation coefficient between the two datasets in fact is 0.9 and their close relationship is illustrated by the scatter plot of Fig. 16c. Nevertheless EPSAT-SG brings a sensible improvement. This result could look surprising but it demonstrates the interest of using a large enough slide window as already discussed in Sect. 6.

A more complete validation comparing EPSAT-SG with other operational rainfall products can be found in Jobard et
Table 5. EPSAT-SG and GPCP-1dd validation statistic parameters fot the AGRHYMET 10-day dataset with a minimum of one gauge per grid-cell.

\begin{tabular}{lcccc}
\hline & Bias & rmsd & $R^{2}$ & skill \\
\hline EPSAT-SG & 5.5 & 17.3 & 0.73 & 0.70 \\
GPCP-1dd & 6.0 & 24.0 & 0.57 & 0.42 \\
\hline
\end{tabular}

al. (2010). The inter-comparison is carried out for ten rainfall estimation methods: three regional method specifically implemented on the West-African area (EPSAT-SG, TAMSAT and RFE.2), three global methods (GPCP-1dd, TRMM-3B42 and GSMAP_MVK) and four real-time methods which are only satellite based (PERSIANN, 3B42-RT, CMORPH and GPI). This comparison is based on 10-day accumulated products computed for three rainy seasons in West-Africa. The main trend is that global methods perform better than realtime ones and they are themselves outperformed by regional methods. Among the regional products, EPSAT-SG gets better results on most of statistical criteria although RFE.2 matches better the validation dataset considering distribution and bias.

Using three dense rain-gauge networks implemented for the AMMA experiment, Roca et al. (2010) developed an innovative approach to compare satellite estimation with ground data taking the various estimation errors into account. Whereas their results are consistent with the ones of Jobard et al. (2010) for 10-day periods, this is not true for shorter periods. When retrieving the diurnal precipitation cycle, EPSATSG appears as less efficient than 3B42. Because of a strong thermal infrared contribution EPSAT-SG is sensitive to the lag between the active convection phase and the development of a stratiform tail. Some improvements can be expected by completing the predictor set by some parameters more closely related to the cloud dynamic. To enhance the diurnal phase estimation, Bergès et al. (2009) proposed a cloud patch growing rate to be integrated as an input parameter.

\section{Conclusion}

EPSAT-SG, a rainfall estimation method, has been presented as a concept frame and its first implementation has been described and commented. The complexity of rainfall related data collection system (satellites, radars and ground networks) compel a production procedure to match with the actual operational environment.

Every rainfall estimation procedure has to consider the weakness of the link between infrared signature and precipitation intensity. EPSAT-SG uses GEO data only for a Rainfall Probability assessment. For the AMMA implementation these probabilities are estimated through a feed forward neural network. The results appear as fairly good and suggest 


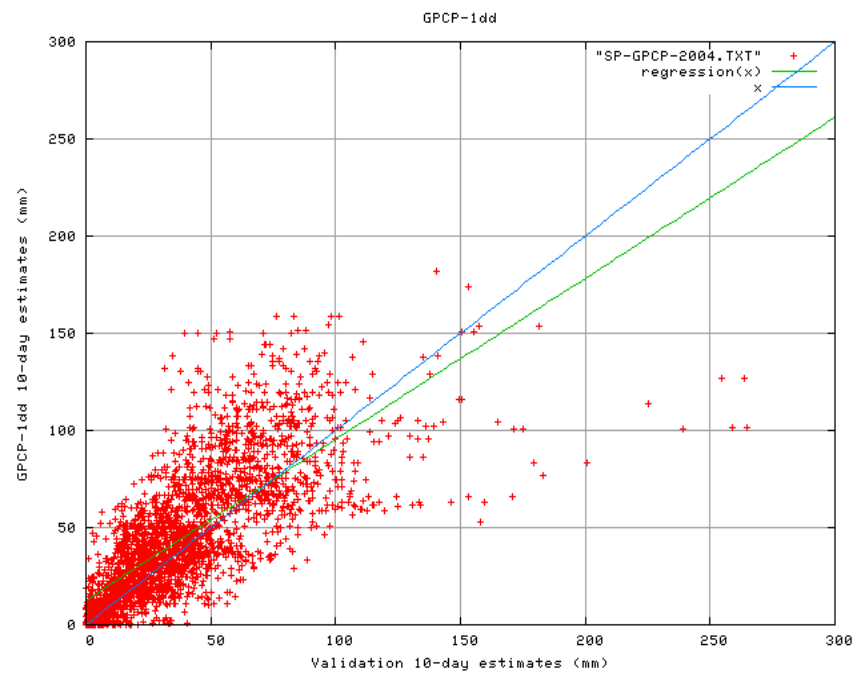

Fig. 16a. Scatter-plot of GPCP-1dd versus validation rain-gauge dataset.

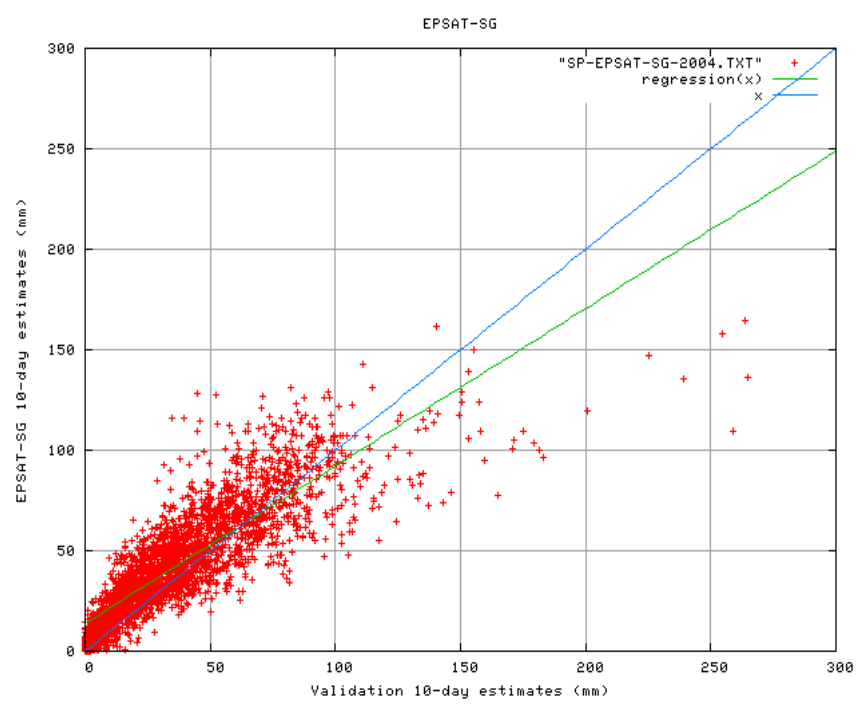

Fig. 16b. Scatter-plot of EPSAT-SG versus validation rain-gauge dataset.

an interesting stability property: once the network is trained, its coefficients could be applied to other time periods without significant loss of accuracy.

The rainfall potential intensity is a new concept introduced in EPSAT-SG. The idea beyond this conditional rainfall intensity is that it takes into account the local aerologic environment whereas the Rainfall Probability retrieves the system tracking information. In a simple case, as the AMMA implementation, it performs a downscaling of a rainfall reference field. But it would also allow to merge various precipitation intensity fields on the basis of their local estimation error.

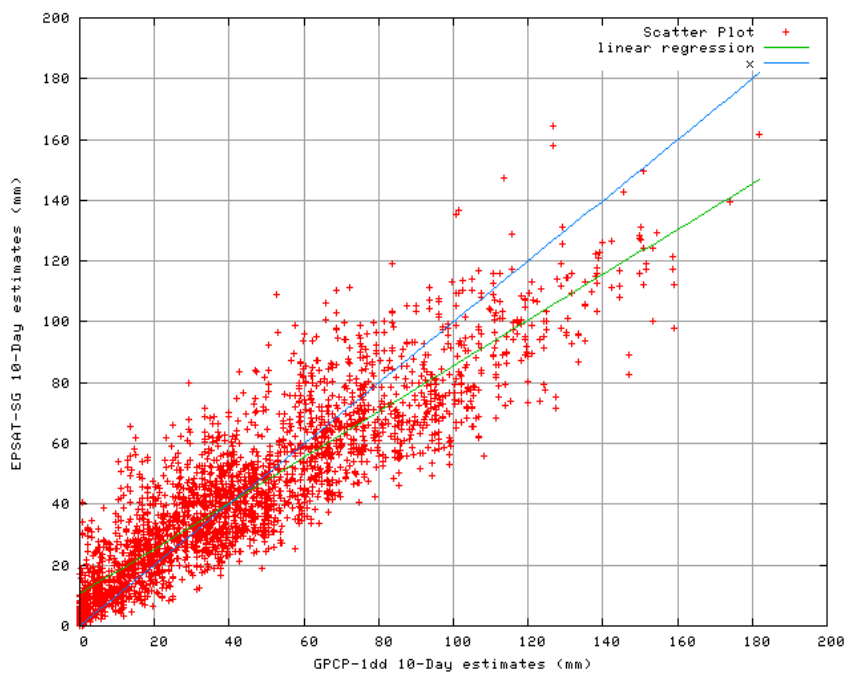

Fig. 16c. Scatter-plot of EPSAT-SG versus GPCP-1dd.

The Estimated Rainfall, which is the product of a Rainfall Probability and a rainfall potential intensity, is obtained at the fine resolution of the GEO satellite $(3 \mathrm{~km}$ and $15 \mathrm{~min}$ for MSG) . Obviously associated errors should be important at this scale. But this resolution allows to match with any final product grid size or any watershed for hydrological models and crop models.

The comparison of EPSAT-SG with GPCP-1dd on the 2004 rainy season shows sensible accuracy improvements even when accumulating on 10-day periods. This result suggest that the downscaling procedure is running efficiently and reduces the error of the ingested rainfall product.

After the integration of EPSAT-SG products in AMMA database, a new implementation has been defined and installed in AGRHYMET Center. This new version, designed to run both in near real time and in differed mode, is currently under evaluation. Moreover the described method can be easily extended to area covered by other GEO satellites than MSG. It can also be tuned to integrate other rainfall reference data sources than GPCP. In the frame of the future MeghaTropiques operational products, the adaptation of EPSAT-SG is developed to ingest all the geostationary satellites covering the full tropical belt.

Acknowledgements. Based on a French initiative, AMMA was built by an international scientific group and is currently funded by a large number of agencies, especially from France, the UK, the US and Africa. It has been the beneficiary of a major financial contribution from the European Community's Sixth Framework Research Programme. Detailed information on scientific coordination and funding is available on the AMMA International web site: http://www.amma-international.org.

Topical Editor F. D'Andrea thanks two anonymous referees for their help in evaluating this paper. 


\section{References}

Adler, R. F. and Negri, A. J.: A Satellite Infrared Technique to Estimate Tropical Convective and Stratiform Rainfall, J. Appl. Meteorol., 27, 30-51, 1988.

Adler, R. F., Huffman, G. J., Chang, A., Ferraro, R., Xie, P., Janowiak, J., Rudolf, B., Schneider, U., Curtis, S., Bolvin, D., Gruber, A., Susskind, J., Arkin, P., and Nelkin, E.: The Version 2 Global Precipitation Climatology Project (GPCP) Monthly Precipitation Analysis (1979-Present), J. Hydrometeorol., 4, 11471167, 2003.

Ali, A., Amani, A., Diedhiou, A., and Lebel, T.: Rainfall Estimation in the Sahel. Part II: Evaluation of Rain Gauge Networks in the CILSS Countries and Objective Intercomparison of Rainfall Products, J. Appl. Meteor. ,44, 1707-1722, 2005.

Arkin, P. A.: The relationship between the fractional coverage of high cloud and rainfall accumulations during GATE over the Barray, Mon. Weather Rev., 107, 1382-1387, 1979.

Arkin, P. A. and Meisner, B. N.: The Relationship between LargeScale Convective Rainfall and Cold Cloud over the Western Hemisphere during 1982-84, Mon. Weather Rev., 115, 51-74, 1987.

Ba, M. B. and Gruber, A.: GOES Multispectral Rainfall Algorithm (GMRA), J. Appl. Meteorol., 40, 1500-1514, 2000.

Balme, M., Vischel, T., Lebel, T., Peugeot, C., and Galle, S.: Assessing the water balance in the Sahel: Impact of small scale rainfall variability on runoff. Part 1: Rainfall variability analysis, J. Hydrol., 331, 336-348, 2006.

Bergès, J. C., Jobard, I., and Roca, R.: A new index to estimate precipitation using cloud growing rate, Geophys. Res. Lett., 36, L08808, doi:10.1029/2008GL036665, 2009.

Coppola, E., Grimes, D. I. F., Verdecchia, M., and Visconti, G.: Validation of Improved TAMANN Neural Network for Operational Satellite-Derived Rainfall Estimation in Africa, J. Appl. Meteor. Climatol., 45, 1557-1572, 2006.

Derrien, M., Farki, B., Harang, L., LeGleau, H., Noyalet, A., Pochic, D., and Sairouni, A.: Automatic cloud detection applied to NOAA-11/AVHRR imagery, Rem. Sens. Environ., 46, 246267, 1993.

Eyre, J. R. and Menzel, P. W.: Retrieval of Cloud Parameters from Satellite Sounder Data: A Simulation Study, J. Appl. Meteorol., 28, 267-275, 1989.

Grimes, D. I. F. and Diop, M.: Satellite-based rainfall estimation for river flow forecast in Africa. I Rainfall estimates and hydrological forecasts, Hydrol. Sci. J., 48(4), 567-584, 2003.

Grody, N. C.: Classification of snow cover and precipitation using the Special Sensor Microwave Imager, J. Geophys. Res., 96, 7423-7435, 1991.

Gruber, A. and Levizzani, V.: Assessment of Global Precipitation Products, WCRP-128, WMO Technical Document, 1430, 57 pp, 2008.

Herman, A., Kumar, V. B., Arkin, P. A., and Kousky, J. V.: Objectively Determined 10-Day African Rainfall Estimates Created for Famine Early Warning Systems, Int. J. Rem. Sens., 18, 21472159, 1997.

Hornik, K., Stinchcombe, M., and White, H.: Multilayer feedforward networks are universal approximators, Neural Networks, 2, 359-366, 1989.

Hornik, K.: Approximation Capabilities of Multilayer Feedforward Networks, Neural Networks, vol. 4, 1991.
Hsu, K., Gao, X., Sorooshian, S., and Gupta, H. V.: Precipitation Estimation from Remotely Sensed Information Using Artificial Neural Networks, J. Appl. Meteorol., 36, 1176-1190, 1997.

Hsu, K., Gupta, H. V., Gao, X., and Sorooshian, S.: Estimation of physical variables from multichannel remotely sensed imagery using neural networks: Application to rainfall estimation, Water Resour. Res., 35, 1605-1618, 1999.

Huffman, G. J., Adler, R. F., Morrissey, M. M., Bolvin, D. T., Curtis, S., Joyce, R., McGavock, B., and Susskind, B.: Global Precipitation at One-Degree Daily Resolution from Multisatellite Observations, J. Hydrometeorol., 2, 36-50, 2001.

Huffman, G. J., Adler, R. F., Bolvin, D. T., Gu, G., Nelkin, E. J., Bowman, K. P., Hong, Y., Stocker, E. F., and Wolff, D. B.: The TRMM Multisatellite Precipitation Analysis (TMPA): Quasiglobal, multiyear, combined-sensor precipitation estimates at fine scales, J. Hydrometeorol., 8, 38-55, 2007.

Iguchi, T., Kozu, T., Meneghini, R., Awaka, J., and Okamoto, K.: Rain-profiling algorithm for the TRMM precipitation radar, J. Appl. Meteor., 39, 2038-2052, 2000.

Inoue, T.: An instantaneous delineation of convective rainfall area using split window data of NOAA-7 AVHRR, J. Meteorol. Soc. Japan, 65, 469-481, 1987.

Jobard, I. and Desbois, M.: Remote sensing of rainfall over the tropical Africa using Meteosat IR imagery; sensitivity to time and space averaging, Int. J. Rem. Sens., 13(14), 2683-2700, 1992.

Jobard, I. and Desbois, M.: Satellite estimation of the tropical precipitation using the METEOSAT ans SSM/I data, Atmos. Res., 34, 285-298, 1994.

Jobard, I., Chopin, F., Bergès, J. C., Ali, A., and Roca, R.: An intercomparison of 10 days satellite precipitation products during West African monsoon, Int. J. Rem. Sens., in press, 2010.

Joyce, R. J., Janowiak, J. E., Arkin, P. A., and Xie, P.: CMORPH: A Method that Produces Global Precipitation Estimates from Passive Microwave and Infrared Data at High Spatial and Temporal Resolution, J. Hydrometeorol., 5, 487-503, 2004.

Kerkmann, J., Rosenfeld, D., and Bridge, G.: Applications of Meteosat Second Generation (MSG) RGB images: Part 4 RGB composites with channels 01-11 and their interpretation, MSG CHANNELS Interpretation Guide, http://oiswww.eumetsat.org/ WEBOPS/msg_interpretation/index.html, 2005.

Kiruno, T.: A rainfall estimation associated with tropical cyclones with the GMS-5 infra-red split windows and water vapour measurements. Proceedings of the Meteorological Satellite Dara Users' Conference, Brussels, 523-528, EUM P 21, ISSN 10113932, 29 September-3 October 1998.

Kubota, T., Shige, S., Hashizume, H., Aonashi, K., Takahashi, N., Seto, S., Hirose, M., Takayabu, Y. N., Ushio, T., Nakagawa, K., Iwanami, K., Kachi, M., and Okamoto, K.: Global precipitation map using satellite-borne microwave radiometers by the GSMaP Project: Production and validation, IEEE Trans. Geosci. Rem. Sens., 45, 2259-2275, 2007.

Kummerow, C., Olson, W. S., and Giglio, L.: A simplified scheme for obtaining precipitation and vertical hydrometer profiles from passive microwave sensors, IEEE Trans. Geosci. Rem. Sens., 34, 1213-1232, 1996.

Kummerow, C., Hong, Y., Olson, W. S., Yang, S., Adler, R. F., McCollum, J., Ferraro, R., Petty, G., Shin, D. B., and Wilheit, T. T.: The Evolution of the Goddard Profiling Algorithm (GPROF) for Rainfall Estimation from Passive Microwave Sensors, J. Appl. 
Meteorol., 40, 1801-1820, 2001.

Lattanzio, A., Watts, P. D., and Govaerts, Y.: Activity report on Physical Interpretation of Warm Water Vapour Pixels, EUMETSAT, Technical Memorandum, 14, 2006.

Levizzani, V., Bauer, P., and Turk, F. J. (Eds.): Measuring precipitation from space, Springer, Dordrecht, 722 pp., 2007.

Milford, J. R. and Dugdale, G.: Estimation of rainfall using geostationary satellite data. Applications of Remote Sensing in Agriculture, Proceedings of 48th Easter School in Agricultural Science, Butterworth, 1990.

Nieman, S. J., Schmetz, J., and Menzel, W. P.: A Comparison of Several Techniques to Assign Heights to Cloud Tracers, J. Appl. Meteorol., 32, 1559-1568, 1993.

Redelsperger, J. L.: The mesoscale organization of deep convection, in: The Physics and Organization of Deep Atmospheric Convection, edited by: Smith, R. K., pp 159-160, Springer, London, 1997.

Richards, F. and Arkin, P. A.: On the relationship between satelliteobserved cloud cover and precipitation, Mon. Weather Rev., 5, 1081-1093, 1981.

Roca, R., Chambon, P., Jobard, I., Kirstetter, P. E., Gosset, M., and Bergès, J. C.: Comparing satellite and surface rainfall products over West Africa at meteorological relevant scales during the AMMA campaign using error estimates, J. Appl. Meteorol. Climatol., in press, 2010.

Rumelhart, D. E., Hinton, G. E., and Williams, R. J.: Learning internal representations by error propagation, in: Parallel Distributed Processing, edited by: Rumelhart, D. E. and McClelland, J. L., MIT Press, 1, 318-362, 1986.

Santurette, P. and Georgiev, C. G.: Weather Analysis and Forecasting: Applying Satellite Water Vapor Imagery and Potential Vorticity Analysis, Academic Press, Burlington, MA, San Diego, London. 179 pp, 2005.
Schmetz, J., Pili P., Tjemkes, S., Just, D., Kerkmann, J., Rota, S., and Ratier, A.: An Introduction to Meteosat Second Generation (MSG), B. Am. Meteorol. Soc., 83, 977-992, 2002.

Takahashi, N., Iguchi, T., Aonashi, K., Awaka, J., Eito, H., Fujita, M., Hashizume, H., Hirose, M., Inoue, T., Kashiwagi, H., Kozu, T., Satoh, S., Seto, S., Shige, S., Shimizu, S., Takayabu, Y., and Okamoto, K.: The Global Satellite Mapping of Precipitation (GSMaP) Project Part II Algorithm and precipitation model development, 2nd TRMM International Science Conference, Nara, 2004.

Tefft, J., McGuire, M., and Maunder, N.: Planning for the future: an assessment of food security early warning systems in sub-Saharan Africa, FAO synthesis report, Rome, TC/D/A0838E/1/11.06/50, 2006.

Todd, M. C., Kidd, C., Kniveton, D., and Bellerby, T. J.: A Combined Satellite Infrared and Passive Microwave Technique for Estimation of Small-Scale Rainfall, J. Atmos. Oceanic Technol., 18, 742-755, 2001.

Vicente, G., Scofield, R. A., and Menzel, W. P.: The operational GOES infrared rainfall estimation technique, B. Am. Meteorol. Soc., 79, 1883-1898, 1998.

Viltard, N., Burlaud, C., and Kummerow, C. D.: Rain Retrieval from TMI Brightness Temperature Measurements Using a TRMM PR-Based Database, J. Appl. Meteorol. Climatol., 45, 455-466, 2006.

Von Storch, H., Langenberg, H., and Feser, F.: A spectral nudging technique for dynamical downscaling purposes, Mon. Weather Rev., 128, 3664-3673, 2000.

Walczak, S. and Cerpa, N.: Heuristic principles for the design of artificial neural networks, Information and software technology, 41, 107-117, 1999.

Wolters, E. L. A., Roebeling, R. A., and Feijt, A. J.: Evaluation of cloud phase retrieval methods for SEVIRI onboard METEOSAT8 using ground-based lidar and cloud radar data, J. Appl. Meteor. Climatol., 47, 1723-1738, 2008. 